\title{
Emotional Fusion and Design Optimization Method Based on Kansei-AD: A Case Study of Laser Additive Manufacturing Equipment
}

\section{Mingyu Ma}

Shenyang University of Technlogy

Xingyu Jiang ( $\square$ xy_jiang9211@sut.edu.cn )

Shenyang University of Technology

Weijun Liu

Shenyang University of Technology

\section{Xu Wang}

Shenyang University of Technology

\section{Chen Zhao}

Shenayng University of Technology

\section{Dan Liu}

Shenayng University of Technology

\section{Guozhe Yang}

Shenyang University of Technology

\section{Original Article}

Keywords: laser additive manufacturing equipment, psychological emotional needs, axiomatic design, Kansei engineering

Posted Date: December 30th, 2020

DOI: https://doi.org/10.21203/rs.3.rs-136149/v1

License: (c) (1) This work is licensed under a Creative Commons Attribution 4.0 International License. Read Full License 


\title{
Emotional Fusion and Design Optimization Method Based on Kansei-AD: A Case Study of Laser Additive Manufacturing Equipment
}

\author{
MA Ming-yu ${ }^{1}$, JIANG Xing-yu ${ }^{1}$, LIU Wei-jun ${ }^{1}$, WANG Xu ${ }^{1}$, ZHAO Chen ${ }^{1}$, LIU Dan ${ }^{1}$, YANG Guo-zhe ${ }^{1}$ \\ 1.School of Mechanical Engineering, Shenyang University of Technology, Shenyang 110870, China
}

\begin{abstract}
To improve the level of integration between the psychological and emotional needs of laser additive manufacturing equipment personnel and the cognitive interactive design of human-machine systems, an emotional optimization design method for laser additive manufacturing equipment based on Kansei engineering and axiomatic design (Kansei-AD) is proposed. By exploring the emotional cognitive process of personnel on equipment, the representation means of the psychological and emotional needs of personnel are clarified. To clarify the psychological and emotional needs of users, the Kansei semantic difference experiment is applied to determine the user domain of axiomatic design. To resolve the difficulty of accurately mapping and expressing between user emotional factors and design elements in the design process, a combination of rough analytic hierarchy process (rough AHP) and quality function deployment (QFD) is used in the functional domain to determine the user Kansei design needs. In addition, the mapping relationship between Kansei design requirements and design requirements is judged by independent axioms of axiomatic design. A matrix of morphological elements-design requirements is constructed, and the morphological design elements that meet the psychological and emotional needs of personnel are determined using the GRA-TOPSIS method. LDM4030 laser coaxial powder feeding equipment is taken as an example to verify the feasibility of the optimization method. The result shows that the method effectively optimizes the design of the equipment according to the psychological and emotional needs of personnel. It provides a new research idea for the psychological and emotional design of laser additive manufacturing equipment.
\end{abstract}

Key words: laser additive manufacturing equipment; psychological emotional needs; axiomatic design; Kansei engineering;

\section{Introduction}

Laser additive manufacturing equipment has become one of the most widely used emerging manufacturing apparatuses in the industry. However, most traditional laser additive manufacturing equipment human-machine system design process and interaction still only meets the interaction requirements at the functional cognitive level. As a result, pleasant design problems, such as humanization and poor comfort, have become increasingly prominent. Operators are no longer satisfied with meeting the needs of laser additive manufacturing equipment only to achieve operational functions and pay more attention to their inner satisfaction and comfort in the interaction process. The degree of equipment emotional design has gradually become an important factor affecting the efficiency of human-computer interactions. Therefore, research is needed on how to effectively integrate the psychological and emotional needs of the operator with the cognitive interaction design of the laser additive manufacturing equipment man-machine system and achieve humanization. This research has important practical significance for improving the human-computer interaction efficiency of laser additive manufacturing equipment.

As a human factors research method for improving the level of emotional design and humanization of equipment for human-machine systems and interactions, Kansei engineering can accurately grasp the

Foundation date:

Received date:0000-00-00;Accept date:0000-00-00

Corresponding author:JIANG Xing-yu,doctor,professor,Tel:18904043009,E-mail:xiakexing1999@126.com 
psychological and emotional factors of personnel and perform emotionalization from the perspective of personnel perception and cognitive psychology ${ }^{[1-2]}$. To achieve product emotional cognition and interaction design, $\mathrm{ALANIZ}^{[3]}$ et al. proposed a new product idea, an emotion-driven innovation method centered on emotions, which defines the emotional intentions for consumers and makes strategic decisions while focusing on creative thinking and emotional design. KONGPRASERT ${ }^{[4]}$ and others used principal component analysis to statistically analyze the customer's personalized emotional intentions and performed clustering interpretation to guide designers to design products that meet customers' personalized emotional needs. SIMEUNOVIC ${ }^{[5]}$ studied how to apply emotional design methods in the development of new concepts for autonomous vehicles. $\mathrm{KIM}^{[6]}$ proposed an emotional variable extraction and classification method combined with self-organizing maps to facilitate the collection and analysis of the user emotional experience. VIEIRA ${ }^{[7]}$ et al. explored the interface rubber keyboard design method that integrates functions and user experience through Kansei engineering methods. GUO Fu ${ }^{[8]}$ combined a back propagation neural network (BPNN) to identify the quantitative relationship between key design factors and emotional dimensions with a genetic algorithm (GA) to search for a design near the optimum. The proposed method helps to design web pages that can satisfy participants' emotions. Li Rui[ ${ }^{[9]}$ et al. studied the design method of the NC machine tool panel based on emotional design, analyzed the emotional level of the machine tool panel, and extracted the design elements of emotional design through the semantic difference method. ZENG Dong ${ }^{[10]}$ discussed the psychological cognitive changes in fire extinguisher users during the operation and improved the design of fire extinguishers by constructing the user's psychological model. JIA Dan-ping ${ }^{[11]}$ and others used the word2vec model and sliding window technology to generate a user's Kansei semantic space and constructed a feature-Kansei emotion model to guide the emotional design of products. In the Kansei interaction design of product modeling, CHENG Yong-sheng ${ }^{[12]}$ and others combined Kansei engineering with AHP to analyze and evaluate the modeling image of automobiles. WANG Xin-ting ${ }^{[13]}$ aimed at the styling design of electric scooters, constructed a multiple regression prediction model of styling design with quantitative type I theory, clarified the correlation between the design factors of appearance elements and Kansei evaluation results, and guided the styling design of electric scooters.

In terms of interactive design decision-making based on Kansei engineering, SHIEH ${ }^{[14]}$ et al. proposed an approach to a hybrid Kansei engineering system (HKES) combining the methodologies of support vector regression (SVR) and MOEAs. Through examples, it was verified that this method could accurately determine the emotional needs of users. Park ${ }^{[15]}$ et al. used Kansei engineering methods to evaluate the effectiveness of vehicle interior warning and auxiliary information design under reduced visibility driving conditions. To determine the relationship between information features and design elements and the driver's expected emotional needs under low visibility conditions, a quantitative type I theory with a two-level hierarchical structure and a Kansei engineering method based on partial least squares were adopted. SUTONO ${ }^{[16]}$ et al. proposed a hybrid method combining grey relational analysis and principal component analysis to solve the multiresponse optimization decision-making problem in Kansei engineering research. HARTONO ${ }^{[17]}$ et al. combined TRIZ theory with Kansei engineering methods and proposed an improved KE method for quantifying customer satisfaction; it assisted designers to quickly find the focus of product design and improve product satisfaction. LI Lan-you ${ }^{[18]}$ quantified the relationship between Kansei intention and modeling genes by constructing a gene double helix structure model of the product and assisted in the decision-making of product portfolio design.

In summary, researchers have achieved certain results for emotional research and the interaction of equipment man-machine systems on Kansei engineering, and they have formed more mature research ideas in the application 
of Kansei engineering methods to explore equipment emotional fusion design methods and decision-making. However, the following problems in the specific laser additive manufacturing equipment design process remain unsolved:

(1) In the process of transforming the emotional factors of Kansei into design factors, it remains necessary to rely on the experience of designers to realize product design. Methods that can accurately express and reflect the relationship between emotional factors and design factors are lacking.

(2) In the design process of traditional Kansei engineering, no design stage can accurately correct and promptly provide feedback to the program, which leads to the completion of the design plan and the beginning of the verification stage. Once the result does not meet expectations, more time and energy are needed to make corrections.

Thus, the axiomatic design ideas are introduced into the optimization process of laser additive manufacturing equipment, and an emotional optimization design method based on Kansei engineering and axiomatic design (Kansei-AD) is proposed in this paper. Based on the application of Kansei engineering to clarify the psychological and emotional needs of the operator, the axiomatic design is used to judge the fit between the design elements and the user's emotional needs and to test the optimization effect of the design plan. This method can solve the problem of underestimating the emotional needs of personnel in the process of laser additive manufacturing equipment human-machine system and interaction design. In addition, it can improve the interaction efficiency and humanization and realize the improvement of the pleasant design of laser additive manufacturing equipment. This work delivers three distinctive innovations:

(1) Combining rough set theory with the analytic hierarchy process (AHP) to overcome the strong subjective weakness of the House of Quality (HOQ) weight setting.

(2) Testing the coupling relationship between the user's Kansei design requirements and the equipment's emotional design requirements through independent axioms and assisting the designer in being able to accurately judge the rationality of Kansei design.

(3) Combining grey relational analysis (GRA) and the TOPSIS method to improve the objectivity and credibility of the final form elements.

The remainder of this paper is organized as follows. The equipment emotional fusion and design optimization model based on Kansei-AD is established in Section 2. Section 3 describes concrete methods of the model. A case study is provided in Section 4. Section 5 discuss the effectiveness of this method, and Section 6 concludes our work.

\section{Equipment emotional fusion and design optimization model}

\subsection{Cognitive process model of laser additive manufacturing equipment operators}

The product emotional fusion design focuses on the emotional experience of users in the process of using the product. Its essence is to explore the generation of emotional factors in the cognitive process of using the product, clarify the emotional needs of the personnel and integrate them into the equipment design process ${ }^{[19-20]}$. Fig. 1 shows the operator's cognitive process model of laser additive manufacturing equipment. In the process of emotional cognition, different forms of interactive information and logical judgments of the operation process are 
transformed into the personnel's attitude and emotion through cognitive psychology and then form the personnel's psychological and emotional factors. The cognition of morphological interaction plays a dominant role in this process, and the operation process has a certain influence on the formation of attitude and emotion. Therefore, to discuss the emotional fusion and design optimization of laser additive manufacturing equipment, the equipment form should be taken as the main entry point for analyzing the psychological and emotional needs of operators during the process of the form interaction.

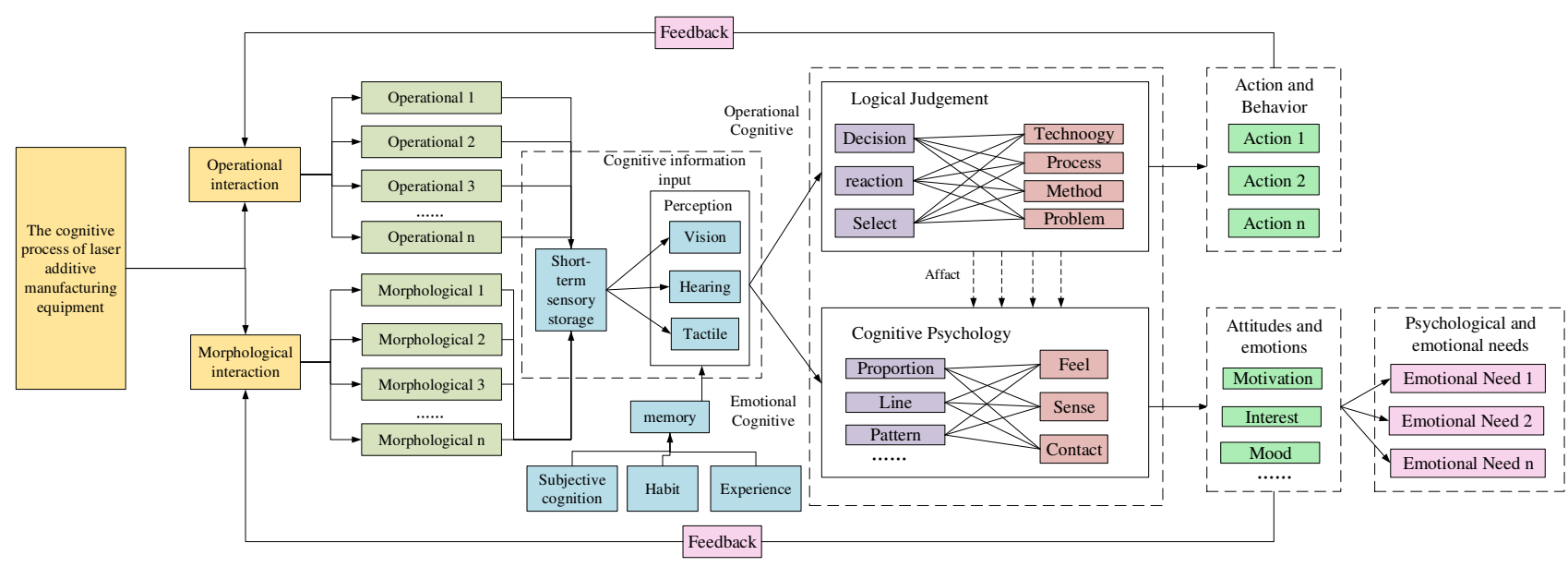

Fig.1 Cognitive process model of the laser additive manufacturing equipment operator

The approach and emotion of personnel can reflect the inner psychological and emotional state and can be represented by semantics. Therefore, when using Kansei engineering for the emotional fusion design of laser additive manufacturing equipment, the operator' s psychological and emotional needs can be determined through the form of semantic experiments. On this basis, the equipment functions and the formation of design elements can be proposed, and the emotional fusion design can be finally launched for optimization. However, as the equipment design work continues to deepen, designers need to constantly review user needs and compare them with the current design situation and judge the integration of emotional needs with the current design based on their own experience. Based on subjective experience, the mapping relationship between the user's psychological and emotional factors and the design elements is usually biased, which affects the effect of the fusion design, and program modification is more complicated and difficult.

Axiomatic design is a method that guides designers to design product functions and product design parameters through mapping methods, or it guides designers to make correct decisions ${ }^{[21]}$. Through the mapping analysis between emotional needs and design elements, designers can accurately grasp the relationship between the user's psychological and emotional factors and design factors, effectively transform the emotional factors into equipment design factors, and improve the accuracy of the emotional integration design process. Therefore, this article combines Kansei engineering with axiomatic design to realize the emotional integration and design optimization of laser additive manufacturing equipment.

\subsection{Emotional fusion and design optimization model based on Kansei-AD}

The axiomatic design divides the product design process into four design domains, namely, the user, functional, physical and process domains ${ }^{[22]}$. Through the hierarchical mapping between the four design domains, designers can easily clarify the relationship between user needs, product functions, product parameters and design solutions $^{[23]}$. 
According to the mapping design process of axiomatic design, the optimization process of laser additive manufacturing equipment based on Kansei-AD proposed in the manuscript is shown in Fig.2. It first determines the psychological and emotional needs of operators through Kansei engineering semantic experiments. Aiming at the problem of accurate reflection between psychological and emotional needs and design factors, the rough AHP-QFD method is used to determine the relationship between user needs and design needs, and clarifies important design needs. Transform important design requirements into functional requirements, and verify the coupling relationship between functional requirements and design parameters through independent axioms. The GRA-TOPSIS method is applied to combine the design parameters with morphological elements, and clarify the morphological elements that should be included in the optimal plan. Use information axioms to verify the optimization effect and realize the humanized design of laser additive manufacturing equipment.

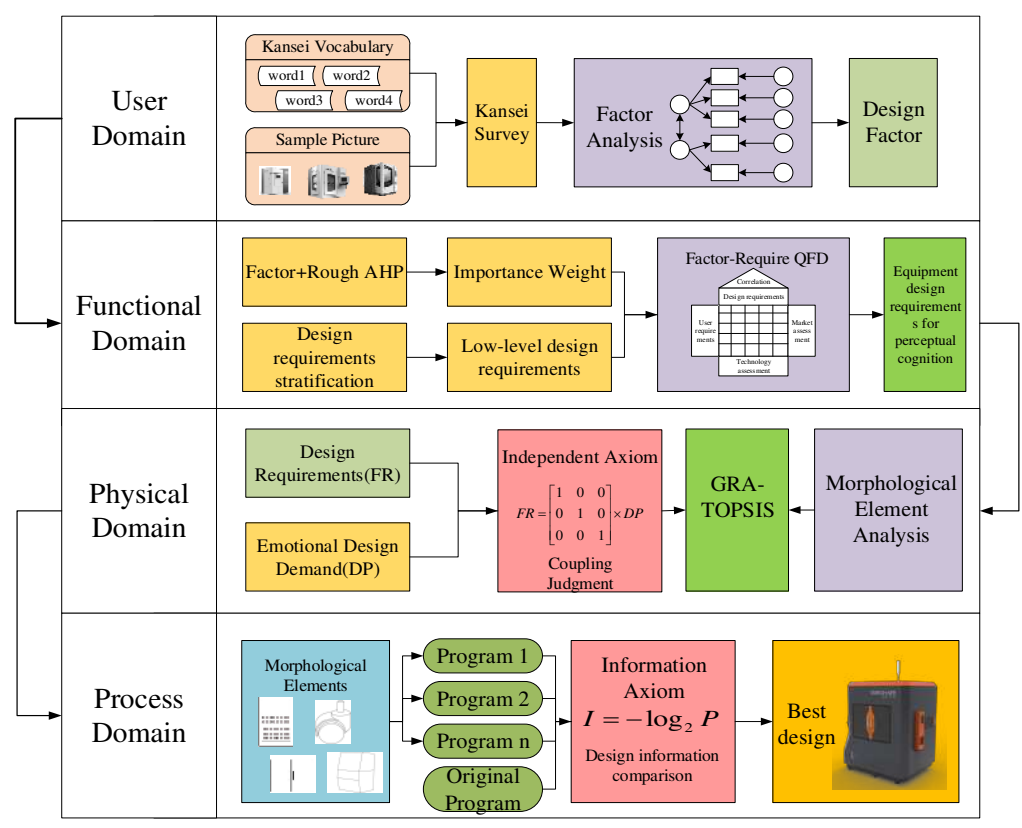

Fig. 2 Emotional fusion and design optimization model of laser additive manufacturing equipment

\section{Optimized model construction}

\subsection{User needs determination based on the Kansei semantic experiment}

The pleasant design of laser additive manufacturing equipment itself is primarily based on the subjective feelings of operators in the process of using the equipment. Therefore, when discussing the emotional optimization design of equipment, it is necessary to thoroughly study the psychological and emotional factors of the operator during use and explore the specific user requirements of the operator for the humanization and comfort of the equipment. The semantic difference experiment method of Kansei engineering is used to explore the needs of operators from the perspective of personnel psychology and emotion.

The semantic difference experiment method converts the Kansei knowledge of personnel into evaluation data by establishing the connection between the semantic space and the representative product, and then it analyzes the design requirements ${ }^{[24]}$. Its advantage is that it can directly determine the product status that operators value most at the psychological and emotional levels. The semantic difference experiment is primarily divided into the following steps:

(1) Establish the Kansei vocabulary space and sample space. Through an investigation and collection of the 
communication media, create the personnel's Kansei image vocabulary for related products (this vocabulary is usually an adjective describing the product form design). Similarly, collect product pictures of the same type as the product. Filter adjectives and pictures, sort out representative adjective pairs and representative samples, and construct the Kansei semantic space and sample space.

(2) Semantic difference investigation. Compile a representative sample Kansei survey experimental questionnaire and invite industry-related practitioners to rate the adjective pairs under each representative sample in the form of a scoring scale. Statistical software is used to count the average scores of adjective pairs under each sample to test the reliability and validity of the questionnaire results.

(3) Semantic factor analysis. The purpose of semantic factor analysis is to use a few factors to describe the relationship between multiple variables and summarize the Kansei cognition of personnel. Using statistical software, the principal component analysis method is used to extract the common factors; the number of factors is judged by outputting the gravel graph and the principal component characteristic value. Under normal circumstances, the component with a characteristic value greater than 1 is taken as a common factor as a summary result of the Kansei cognition of the personnel.

\subsection{Determination of design requirements based on rough AHP-QFD}

The emotional fusion design of laser additive manufacturing equipment should be designed around user needs to meet the pleasant requirements of the equipment. However, because the specific feelings of the operators are different, in the actual design process, the relative importance of the factors must be determined, and the best Kansei factors recognized by most operators must be found to optimize the design as the focus of the design. Quality function deployment (QFD) based on meeting user needs reasonably transforms Kansei factors into product technical goals to clarify specific design requirements that should be focused on ${ }^{[25]}$. However, in the traditional QFD method, weight determination is usually calculated in the form of a summation. It is subjective and arbitrary. In this paper, rough number theory is combined with the AHP method to calculate the weight value of the human Kansei factor with the rough AHP to solve the problem of strong subjectivity in the process of QFD weight determination ${ }^{[26-27]}$.

Suppose $U$ is the universe which contains all the objects, and $R$ is the set of classes that cover all the objects in $U$, where

$$
R=\left\{\begin{array}{lllll}
R_{1} & R_{2} & R_{3} & \ldots & R_{s}
\end{array}\right\}, R_{1}<R_{2}<\ldots<R_{s}
$$

$Y$ is an arbitrary object of U.For any element in the set, $\forall Y \in U, R_{t} \in R, 1 \leq t \leq s$. For the lower approximation $\underline{\operatorname{Apr}}\left(R_{t}\right)$, upper approximation $\overline{\operatorname{Apr}}\left(R_{t}\right)$,lower limit $\underline{\operatorname{Lim}}\left(R_{t}\right)$, upper limit $\overline{\operatorname{Lim}}\left(R_{t}\right)$, we have

$$
\begin{aligned}
& \underline{\operatorname{Apr}}\left(R_{t}\right)=\cup\left\{Y \in U \mid R(Y) \leq R_{t}\right\} \\
& \overline{\operatorname{Apr}}\left(R_{t}\right)=\cup\left\{Y \in U \mid R(Y) \geq R_{t}\right\}
\end{aligned}
$$


Then, $R_{t}$ can be represented by a rough number $R N\left(R_{t}\right)$, which is determined by its corresponding lower limit and upper limit where

$$
\begin{aligned}
& \underline{\operatorname{Lim}}\left(R_{t}\right)=\frac{\sum R(Y) \mid Y \in \underline{\operatorname{Apr}}\left(R_{t}\right)}{M_{L}} \\
& \overline{\operatorname{Lim}}\left(R_{t}\right)=\frac{\sum R(Y) \mid Y \in \overline{\operatorname{Apr}}\left(R_{t}\right)}{M_{U}} \\
& R N\left(R_{t}\right)=\left[\underline{\operatorname{Lim}}\left(R_{t}\right), \overline{\operatorname{Lim}}\left(R_{t}\right)\right]
\end{aligned}
$$

where $M_{L}, M_{U}$ are the number of objects that contained in $\underline{\operatorname{Apr}}\left(R_{t}\right)$ and $\overline{\operatorname{Apr}}\left(R_{t}\right)$. Based on the rough number, the procedure of the rough AHP is described as follows:

Step 1: Experts evaluate the relative importance of the criteria, form an evaluation matrix A and conduct a consistency test. When the consistency test value satisfies $\mathrm{CR}<0.1$, the consistency test can be considered as passed.

$$
A=\left[\begin{array}{cccc}
1 & x_{12}^{t} & \ldots & x_{1 n}^{t} \\
x_{21}^{t} & 1 & \ldots & x_{2 n}^{t} \\
\ldots & \ldots & \ldots & \ldots \\
x_{n 1}^{t} & x_{n 2}^{t} & \ldots & 1
\end{array}\right]
$$

Step 2: Conduct an AHP survey and construct a group of pairwise comparison matrices. Set up m evaluation experts, integrate the $\mathrm{n}$-dimensional evaluation matrix of $\mathrm{m}$ experts to construct an integrated judgment matrix, and set it as B

$$
B=\left[\begin{array}{cccc}
1 & x_{12} & \ldots & \mathscr{X}_{1 n} \\
\mathcal{X}_{2} Q & 1 & \ldots & \mathscr{X}_{2 n} \\
& \mathscr{O} Q & \ldots & \\
\ldots & x_{g h} & \ldots & \ldots \\
X_{n 1} & x_{n} Q & \ldots & 1
\end{array}\right]
$$

where $\mathcal{X}_{g h} \mathscr{W}=\left\{x_{g h}^{1}, x_{g h}^{2}, \ldots, x_{g h}^{m}\right\}$, and $\mathcal{X}_{g h}$ is the sequence of the relative importance of criterion $\mathrm{g}$ on criterion $\mathrm{h}$.

Step 3: Transform each importance set into a rough set. According to Eqs. (2)-(5) for representation

$$
R N\left(\mathscr{X}_{g h}\right)=\left\{\left[x_{g h}^{1 L}, x_{g h}^{1 U}\right],\left[x_{g h}^{2 L}, x_{g h}^{2 U}\right], \ldots,\left[x_{g h}^{t L}, x_{g h}^{t U}\right], \ldots,\left[x_{g h}^{m L}, x_{g h}^{m U}\right]\right\}
$$

where $x_{g h}^{t L}$ is the lower limit of $R N\left(x_{g h}^{t}\right)$, and $x_{g h}^{t U}$ is the upper limit of $R N\left(x_{g h}^{t}\right)$. Perform normalization 
processing according to Eq. (10) and Eq. (11) to construct a rough judgment matrix, as shown in Eq. (12)

$$
\begin{aligned}
& x_{g h}^{L}=\frac{x_{g h}^{1 L}+x_{g h}^{2 L}+\ldots+x_{g h}^{m L}}{m} \\
& x_{g h}^{U}=\frac{x_{g h}^{1 U}+x_{g h}^{2 U}+\ldots+x_{g h}^{m U}}{m} \\
& M=\left[\begin{array}{cccc}
{[1,1]} & {\left[x_{12}^{L}, x_{12}^{U}\right]} & \ldots & {\left[x_{1 n}^{L}, x_{1 n}^{U}\right]} \\
{\left[x_{21}^{L}, x_{21}^{U}\right]} & {[1,1]} & \ldots & {\left[x_{2 n}^{L}, x_{2 n}^{U}\right]} \\
\ldots & \ldots & \ldots & \ldots \\
{\left[x_{n 1}^{L}, x_{n 1}^{U}\right]} & {\left[x_{n 2}^{L}, x_{n 2}^{U}\right]} & \ldots & {[1,1]}
\end{array}\right]
\end{aligned}
$$

Step 4. Calculate the rough weight $w_{g}$ of each criterion:

$$
\begin{gathered}
w_{g}=\left[\sqrt[n]{\prod_{h=1}^{n} x_{g h}^{L}}, \sqrt[n]{\prod_{h=1}^{n} x_{g h}^{U}}\right] \\
w_{g}^{\prime}=\frac{w_{g}}{\max \left(w_{g}^{U}\right)}=\left[w_{g}^{L^{\prime}}, w_{g}^{U^{\prime}}\right]
\end{gathered}
$$

Finally, the standard weight is obtained

$$
\begin{aligned}
& a_{i}^{\prime}=\frac{w_{i}^{L^{\prime}}+w_{i}^{U^{\prime}}}{2} \\
& a_{i}=a^{\prime} / \sum a_{i}^{\prime}
\end{aligned}
$$

The relative weight of each Kansei factor is obtained from Eq. (16), and the best Kansei cognition of the operator of laser additive manufacturing equipment is determined. The Kansei factors (user needs) and their weights of personnel and the design needs are imported into the House of Quality, and the quantitative relationship between Kansei factors and design needs is analyzed to determine that the equipment meets the design needs of Kansei cognition. Let $n_{i}$ be the relative weight of the Kansei factor and $a_{i j}$ be the size of the correlation between the Kansei factor $i$ and the design requirement $j$. Then the relative importance $\alpha_{j}$ and importance $\beta_{j}$ of the design requirements can be expressed as: 


$$
\begin{aligned}
& \alpha_{j}=\beta_{j} / \sum_{j=1}^{m} \beta_{j} \\
& \beta_{j}=\sum_{i=1}^{n} n_{i} \times a_{i j}
\end{aligned}
$$

\subsection{Design factors determination based on independent axiom and GRA-TOPSIS}

After determining the Kansei design requirements of laser additive manufacturing equipment, this paper transforms the equipment design requirements into functional requirements in axiomatic design, proposes the corresponding emotional fusion design requirements for functional requirements, and transforms them into design parameters of axiomatic design. Next, we analyze the mapping relationship between equipment function requirements and design parameters through the independence axiom and use the design parameters to determine the form elements that meet the requirements of equipment emotional fusion design. The axiom of independence avoids redundant design in the design process and simplifies the design content by judging the independence between functional requirements and design parameters ${ }^{[28]}$. The design equation of the independence axiom can be expressed as:

$$
F R=A \times D P
$$

where $F R$ represents the functional requirements, $A$ is the independence axiom design matrix, and $D P$ is the design parameter. According to the different mapping relationships between functional requirements and design parameters, $A$ has three forms:

(1) Noncoupling matrix. It represents a one-to-one mapping relationship between functional requirements and design parameters. It meets the requirements of axiomatic design, and its expression is

$$
F R=\left[\begin{array}{lll}
1 & 0 & 0 \\
0 & 1 & 0 \\
0 & 0 & 1
\end{array}\right] \times D P
$$

(2) Quasi-coupling matrix. It meets the requirements of axiomatic design. It can be decoupled and transformed into a noncoupling matrix by redefining the functional domain or physical domain. Its expression is

$$
F R=\left[\begin{array}{lll}
1 & 0 & 0 \\
1 & 1 & 0 \\
1 & 1 & 1
\end{array}\right] \times D P
$$

(3) Coupling matrix. The coupling matrix does not meet the requirements of axiomatic design. It must be redefined to decouple the coupling matrix into a quasi-coupled matrix or a noncoupled matrix. Its expression is 


$$
F R=\left[\begin{array}{lll}
1 & 0 & 1 \\
0 & 1 & 1 \\
0 & 1 & 0
\end{array}\right] \times D P
$$

When the independent axiom test results show a noncoupling relationship or a quasi-coupling relationship, the emotional fusion design requirements of laser additive manufacturing equipment meet the Kansei design requirements of personnel for equipment. We construct and score a design requirement-form element evaluation matrix with equipment form elements as the evaluation object and emotional fusion design requirements as the evaluation index, and we solve the weight value of each form element. The equipment form elements that meet the psychological and emotional needs of personnel can be obtained. Based on this result, the GRA-TOPSIS method is used to solve the evaluation matrix. This method can fully use the sample data and avoid the disadvantage of the traditional TOPSIS method, which has high accuracy and credibility ${ }^{[29-30]}$. Suppose there are $\mathrm{m}$ morphological elements and $\mathrm{n}$ design requirements. They form the evaluation matrix $\mathrm{K}$

$$
K=\left[\begin{array}{cccc}
k_{11} & k_{12} & \ldots & k_{1 n} \\
k_{21} & k_{22} & \ldots & k_{2 n} \\
\ldots & \ldots & k_{i j} & \ldots \\
k_{m 1} & k_{m 2} & \ldots & k_{m n}
\end{array}\right]
$$

where $K_{i j}$ is a score for the degree to which each morphological element meets the design requirements. Then, the steps for applying the GRA-TOPSIS method to calculate the weight of morphological elements are as follows:

Step 1. According to Eq. (24), the evaluation matrix $K$ is normalized to form a standardized matrix $V$, where $V_{i j}$ is the standardized morphological element score.

$$
\begin{gathered}
v_{i j}=k_{i j} / \sqrt{\sum_{i=1}^{m} k_{i j}^{2}} \\
V=\left[\begin{array}{cccc}
v_{11} & v_{12} & \ldots & v_{1 n} \\
v_{21} & v_{22} & \ldots & v_{2 n} \\
\ldots & \ldots & \ldots & \ldots \\
v_{m 1} & v_{m 2} & \ldots & v_{m n}
\end{array}\right]
\end{gathered}
$$

Step 2. The maximum and minimum values of each column in the standardized matrix $\mathrm{V}$ are judged to form the set of positive ideal solutions and the set of negative ideal solutions shown in Eqs. (26)-(27). On this basis, the gray correlation coefficients between the morphological elements and the positive and negative ideal solutions are solved using Eqs. (28)-(29)

$$
\begin{aligned}
& V^{+}=\left\{V_{1}^{+}, V_{2}^{+}, \ldots, V_{n}^{+}\right\}, V_{j}^{+}=\max _{i}\left(v_{i j}\right) \\
& V^{-}=\left\{V_{1}^{-}, V_{2}^{-}, \ldots, V_{n}^{-}\right\}, V_{j}^{-}=\min _{i}\left(v_{i j}\right)
\end{aligned}
$$




$$
\begin{aligned}
r_{i j}^{+} & =\frac{\min _{i} \min _{j}\left|V_{j}^{+}-v_{i j}\right|+\rho \max _{i} \max _{j}\left|V_{j}^{+}-v_{i j}\right|}{\left|V_{j}^{+}-v_{i j}\right|+\rho \max _{i} \max _{j}\left|V_{j}^{+}-v_{i j}\right|} \\
r_{i j}^{-} & =\frac{\min _{i} \min _{j}\left|V_{j}^{-}-v_{i j}\right|+\rho \max _{i} \max _{j}\left|V_{j}^{-}-v_{i j}\right|}{\left|V_{j}^{-}-v_{i j}\right|+\rho \max _{i} \max _{j}\left|V_{j}^{-}-v_{i j}\right|}
\end{aligned}
$$

where $\rho$ is the resolution coefficient, which is usually $0.5 . r_{i j}^{+}$and $r_{i j}^{-}$are the gray correlation coefficients between the morphological elements and the positive and negative ideal solutions, respectively.

Step 3. According to Eqs. (30)-(31), calculate the gray correlation degree and closeness between the morphological elements and the positive and negative ideal solutions. They are represented by $r_{i}^{ \pm}$and $d_{i}^{ \pm}$ respectively.

$$
\begin{gathered}
r_{i}^{ \pm}=\sum_{j=1}^{n} r_{i j}^{ \pm} / n \\
d_{i}^{ \pm}=\sqrt{\sum_{j=1}^{n}\left(v_{i j}-v_{j}^{ \pm}\right)^{2}}
\end{gathered}
$$

Step 4. The gray correlation degree and the proximity degree are processed in a dimensionless manner and integrated into the Euclidean distance, as shown in Eqs. (32)-(34).

$$
\begin{gathered}
D_{i}^{ \pm}=\frac{d_{i}^{ \pm}}{\max _{i} d_{i}^{ \pm}}, R_{i}^{ \pm}=\frac{r_{i}^{ \pm}}{\max _{i} r_{i}^{ \pm}} \\
P_{i}^{+}=\lambda D_{i}^{+}+\gamma R_{i}^{-} \\
P_{i}^{-}=\lambda D_{i}^{-}+\gamma R_{i}^{+}
\end{gathered}
$$

where $\lambda$ and $\gamma$ are the coefficients reflecting the degree of attention between the form elements and the emotional fusion design requirements, and they take $\lambda=\gamma=0.5$. On this basis, calculate the final score of the equipment form elements, denoted $S$

$$
S_{i}=\frac{P_{i}^{+}}{P_{i}^{+}+P_{i}^{-}}
$$

According to Eq.(35), the final scores of each form element of the equipment are calculated and compared. The form element with the highest score is the perceptual optimization design element of laser additive manufacturing equipment that meets the psychological and emotional needs of personnel.

\subsection{Design optimization plan determination}


After determining the morphological elements of the laser additive manufacturing equipment through the independent axioms, the information axioms of axiomatic design are used to simplify the uncertainty and uncertainty in the design process and other factors that affect the equipment design process, and the design is selected so that the scheme with the least information content is the optimal design scheme. The design information content of the information axiom is expressed by Eq. (36)

$$
I=-\log _{2} P
$$

where $I$ is the content of design information contained in the design of a certain program, $P$ is the probability that the program meeting the user's expectations will be successful, which is determined by the matching degree of the actual and feasible design quantity to meet user's needs and the amount of user demand design quantity expected. Specifically, it is expressed as:

$$
P=\frac{\text { Actual and feasible design quantity to meet user needs }}{\text { The amount of user demand design quantity expected }}
$$

When the actual and feasible design quantity is higher than the user' s expected demand design quantity, the probability of success of the design scheme can be considered high. According to Eq. (37), the higher the probability of success of the scheme is, the smaller the corresponding amount of information contained is. Under normal circumstances, the demand design quantity expected by a certain product user is usually fixed. Therefore, to meet the requirement of less program information, it is necessary to ensure that the amount of practical and feasible designs that meets the needs of users is large. The actual and feasible design quantity is usually related to the complexity of the design scheme, the operability and the satisfaction of user needs.

\section{Case study}

This article takes LDM4030 coaxial powder feeding laser additive manufacturing equipment as the specific optimization object (as shown in Fig. 3). According to the determined morphological elements and specific objects, multiple optimization schemes were designed. We analyze the optimization plan with the information axioms in the axiomatic design and select the optimal design plan. Finally, a Kansei comparison investigation between the optimal program and the optimized object is conducted to test the effect of the optimized program.

This paper first constructed the semantic space and representative samples of laser additive manufacturing equipment. A total of 70 adjectives that directly or indirectly describe equipment were collected through multimedia methods, such as the internet, magazines, and newspapers. Invited researchers and operators engaged in laser additive manufacturing equipment to group and analyze the vocabulary through the KJ method, and finally, 15 adjectives were obtained. Additionally, we determined that their antonyms constitute a semantic space composed of 15 pairs of adjectives, as shown in Tab. 1. We collected the pictures of laser additive manufacturing equipment, screened out similar pictures, and obtained 12 representative pictures, as shown in Tab. 2. 




Fig. 3 LDM4030 coaxial powder feeding laser additive manufacturing equipment

Tab. 1 Semantic spatial adjective pairs for laser additive manufacturing equipment

\begin{tabular}{|c|c|}
\hline Adjective pairs & Code \\
\hline Dangerous-Safe & Q1 \\
\hline Not durable-Durable & Q2 \\
\hline Empty-Full & Q3 \\
\hline Amateur-Professional & Q4 \\
\hline Implicit-Publicity & Q5 \\
\hline Alternative-Usual & Q6 \\
\hline Dull-Cheerful & Q7 \\
\hline Bulky-Flexible & Q8 \\
\hline Dehumanized-Humanized & Q9 \\
\hline Mechanical-Intelligent & Q10 \\
\hline Traditional-Avant-garde & Q11 \\
\hline Natural-Man-made & Q12 \\
\hline Individual-General & Q13 \\
\hline Dysfunctional-Coordinated & Q14 \\
\hline
\end{tabular}


Tab. 2 Representative pictures of laser additive manufacturing equipment

\begin{tabular}{|l|l|l|l|}
\hline & & & \\
\hline
\end{tabular}

We then integrated the semantic space with the representative pictures to compile a Kansei semantic questionnaire for laser additive manufacturing equipment. The questionnaire is scored on a five-level interval with an integer ranging from -2 to +2 and presented in the form of a five-level Likert scale. The survey subjects are primarily operators engaged in laser additive manufacturing equipment, design researchers, production personnel engaged in related equipment, and teachers and students in related majors as a supplement. The subjects scored the Kansei adjective pairs under each sample, and we analyzed the Kansei cognitive intentions of the personnel. A total of 57 questionnaires were collected, and 52 valid questionnaires were obtained through screening. We took the average of the Kansei adjective scores of each representative sample in the 52 valid questionnaires and obtained the statistical results shown in Tab. 3. Through reliability analysis, the reliability of the questionnaire Cronbach is 0.892 , and the statistical results are true and credible.

Tab. 3 Kansei semantic survey questionnaire statistical results

\begin{tabular}{cccccccccccccccc}
\hline & Q1 & Q2 & Q3 & Q4 & Q5 & Q6 & Q7 & Q8 & Q9 & Q10 & Q11 & Q12 & Q13 & Q14 & Q15 \\
\hline P1 & 1.17 & 1.0 & 1.02 & 1.38 & 0.21 & 0.83 & 0.38 & 0.35 & 0.87 & 0.96 & 0.67 & 1.37 & 0.79 & 0.85 & 0.98 \\
P2 & 1.33 & 1.1 & 0.9 & 1.25 & 0.17 & 0.56 & 0.38 & 0.96 & 1.1 & 1.25 & 0.87 & 1.35 & 0.56 & 1.02 & 0.75 \\
P3 & 1.33 & 1.33 & 1.0 & 1.37 & 0.27 & 0.63 & 0.38 & 0.29 & 0.9 & 1.33 & 0.73 & 1.12 & 0.65 & 0.83 & 0.73 \\
P4 & 1.0 & 1.1 & 0.71 & 1.19 & 0.15 & 0.94 & 0.12 & 0.29 & 0.56 & 0.44 & 0.33 & 1.17 & 1.0 & 0.73 & 0.33
\end{tabular}




\begin{tabular}{lllllllllllllllllll}
\hline P5 & 1.06 & 0.75 & 0.65 & 1.06 & 0.25 & 0.54 & 0.21 & 0.44 & 0.81 & 0.85 & 0.46 & 1.06 & 0.56 & 0.58 & 0.48 \\
P6 & 1.27 & 1.13 & 0.65 & 1.23 & 0.12 & 0.5 & 0.21 & 0.29 & 0.54 & 0.79 & 0.35 & 1.13 & 0.56 & 0.69 & 0.42 \\
P7 & 0.92 & 1.25 & 0.88 & 1.62 & 0.52 & 0.62 & 0.54 & 0.1 & 0.75 & 1.04 & 0.73 & 1.13 & 0.46 & 0.71 & 0.63 \\
P8 & 1.37 & 1.35 & 1.31 & 1.42 & 0.6 & 0.44 & 0.75 & 0.75 & 1.1 & 1.27 & 0.9 & 1.08 & 0.63 & 1.0 & 1.15 \\
P9 & 1.38 & 1.31 & 1.15 & 1.27 & 0.6 & 0.63 & 0.69 & 0.63 & 1.02 & 1.21 & 0.83 & 1.21 & 0.62 & 1.0 & 0.9 \\
P10 & 1.21 & 1.08 & 1.04 & 1.35 & 0.62 & 0.77 & 0.63 & 0.58 & 1.02 & 1.1 & 0.88 & 1.12 & 0.63 & 0.92 & 0.67 \\
P11 & 1.17 & 1.08 & 1.06 & 1.33 & 0.81 & 0.54 & 0.6 & 0.19 & 0.9 & 0.96 & 0.65 & 1.13 & 0.37 & 0.88 & 0.88 \\
P12 & 1.19 & 1.15 & 1.06 & 1.31 & 0.6 & 0.69 & 0.63 & 0.94 & 1.1 & 1.17 & 1.0 & 1.17 & 0.71 & 0.98 & 1.06
\end{tabular}

Next, we determined the adjective pair that summarizes the psychological and emotional cognition of laser additive manufacturing equipment operators through factor analysis, that is, the user needs. To ensure the correlation between adjective pairs and the sample, the correlation degree is first checked before the factor analysis, and the words with a correlation degree less than 0.4 are removed. Tab. 4 shows the correlation coefficient of each adjective after reliability analysis. Because the correlation coefficient of Q12 is less than 0.4 , the Q12 "natural-man-made" adjective pair is excluded.

Tab. 4 Adjective pair correlation statistics

\begin{tabular}{|c|c|c|c|c|}
\hline $\begin{array}{l}\text { Adjective } \\
\text { Pairs }\end{array}$ & $\begin{array}{c}\text { Scale Mean if Item } \\
\text { Deleted }\end{array}$ & $\begin{array}{l}\text { Scaled Variance if } \\
\text { Item Deleted }\end{array}$ & $\begin{array}{l}\text { Corrected Item-Total } \\
\text { Correlation }\end{array}$ & $\begin{array}{c}\text { Cronbach's Alpha if Item } \\
\text { Deleted }\end{array}$ \\
\hline Q1 & 10.6058 & 4.081 & .480 & .888 \\
\hline Q2 & 10.7283 & 3.970 & .594 & .884 \\
\hline Q3 & 10.9017 & 3.628 & .936 & .869 \\
\hline Q4 & 10.5558 & 4.143 & .519 & .887 \\
\hline Q5 & 11.4742 & 3.820 & .567 & .885 \\
\hline Q6 & 11.2525 & 4.810 & -.455 & .917 \\
\hline Q7 & 11.4500 & 3.574 & .882 & .870 \\
\hline Q8 & 11.4467 & 3.665 & .607 & .884 \\
\hline Q9 & 11.0192 & 3.689 & .751 & .876 \\
\hline Q10 & 10.8725 & 3.496 & .866 & .870 \\
\hline Q11 & 11.1775 & 3.504 & .951 & .866 \\
\hline Q12 & 10.6225 & 4.366 & .262 & .894 \\
\hline Q13 & 11.2642 & 4.818 & .516 & .915 \\
\hline
\end{tabular}




\begin{tabular}{lllll}
\hline Q14 & 11.0292 & 3.873 & .879 & .876 \\
Q15 & 11.1383 & 3.482 & .885 & .869 \\
\hline
\end{tabular}

The variance interpretation results and gravel graph results of each adjective pair after factor analysis are shown in Tab. 5 and Fig. 4. The results in Tab. 5 show that the cumulative explanatory rate of the variance of the first four factors is $90.516 \%$, and the percentages of variance of the four factors after rotation are all greater than $10 \%$. According to the results of the gravel map, the eigenvalues of the first four points have greater differences, and the subsequent points have smaller differences, so the image has an obvious turning point at the fourth point. These results show that the four factors can summarize all adjective pairs well.

Tab. 5 Variance interpretation results of adjective pairs

\begin{tabular}{|c|c|c|c|c|c|c|c|c|c|}
\hline \multirow[b]{2}{*}{ Components } & \multicolumn{3}{|c|}{ Initial Eigenvalues } & \multicolumn{3}{|c|}{ Extraction Sums of Squared Loadings } & \multicolumn{3}{|c|}{ Rotation Sums of Squared Loadings } \\
\hline & Total & $\begin{array}{c}\% \text { of } \\
\text { Variance }\end{array}$ & $\begin{array}{c}\text { Cumulative } \\
\%\end{array}$ & Total & $\begin{array}{c}\% \text { of } \\
\text { Variance }\end{array}$ & $\begin{array}{c}\text { Cumulative } \\
\%\end{array}$ & Total & $\begin{array}{c}\% \text { of } \\
\text { Variance }\end{array}$ & $\begin{array}{c}\text { Cumulative } \\
\%\end{array}$ \\
\hline 1 & 8.513 & 60.808 & 60.808 & 8.513 & 60.808 & 60.808 & 5.189 & 37.068 & 37.068 \\
\hline 2 & 1.735 & 12.390 & 73.197 & 1.735 & 12.390 & 73.197 & 2.745 & 19.606 & 56.674 \\
\hline 3 & 1.262 & 9.012 & 82.209 & 1.262 & 9.012 & 82.209 & 2.635 & 18.824 & 75.497 \\
\hline 4 & 1.163 & 8.307 & 90.516 & 1.163 & 8.307 & 90.516 & 2.103 & 15.019 & 90.516 \\
\hline 5 & .407 & 2.910 & 93.426 & & & & & & \\
\hline 6 & .330 & 2.358 & 95.785 & & & & & & \\
\hline 7 & .232 & 1.660 & 97.445 & & & & & & \\
\hline 8 & .207 & 1.479 & 98.924 & & & & & & \\
\hline 9 & .101 & .722 & 99.646 & & & & & & \\
\hline 10 & .032 & .226 & 99.872 & & & & & & \\
\hline 11 & .018 & .128 & 100.000 & & & & & & \\
\hline 12 & $\begin{array}{c}5.632 \mathrm{E}- \\
16\end{array}$ & $4.017 \mathrm{E}-15$ & 100.000 & & & & & & \\
\hline 13 & $\begin{array}{c}1.847 \mathrm{E}- \\
16\end{array}$ & $1.320 \mathrm{E}-15$ & 100.000 & & & & & & \\
\hline 14 & $\begin{array}{c}-2.648 \mathrm{E}- \\
16\end{array}$ & $\begin{array}{c}-1.892 \mathrm{E}-1 \\
5\end{array}$ & 100.000 & & & & & & \\
\hline
\end{tabular}

Extraction method: Principal Component Analysis 


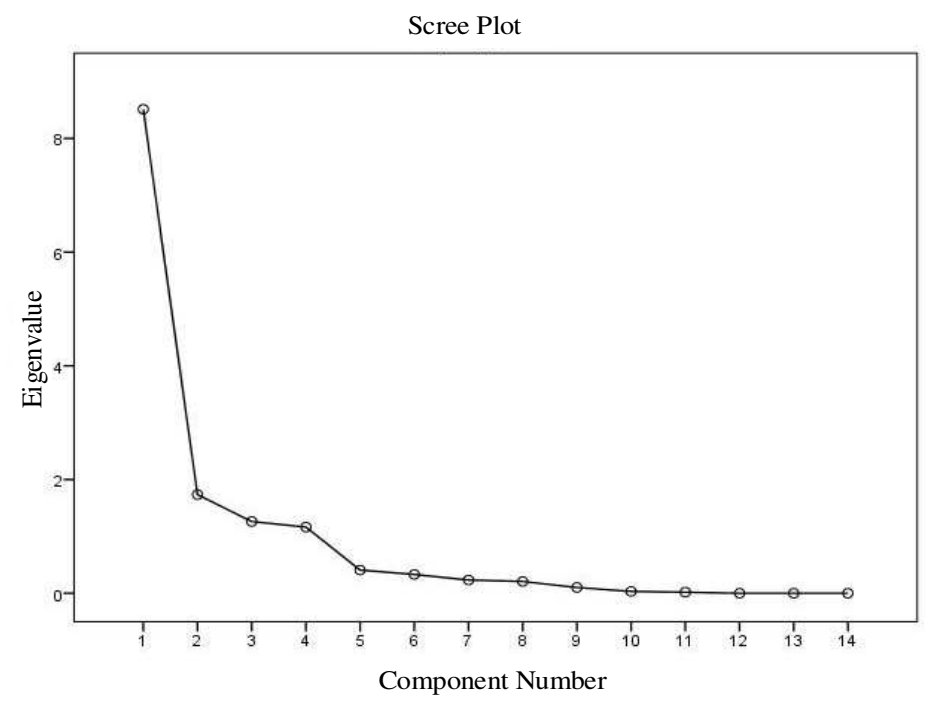

Fig. 4 Factor analysis lithograph results

The load matrix of each adjective pair after factor analysis is shown in Tab. 6 . The semantic space formed by the 14 groups of adjective pairs is composed of four types of factors, namely, humanity factors, professional factors, personality factors, and safety factors. So far, the emotional user needs of the operators of laser additive manufacturing equipment obtained through the Kansei semantic difference experiment can be summarized as humanity, professionalism, personality, and safety.

Tab. 6 Factor analysis loading matrix

\begin{tabular}{|c|c|c|c|c|}
\hline \multirow{2}{*}{ Adjective pairs } & \multicolumn{4}{|c|}{ Components } \\
\hline & 1 & 2 & 3 & 4 \\
\hline Q9 & .896 & .102 & .252 & -.051 \\
\hline Q8 & .849 & -.299 & .084 & .296 \\
\hline Q11 & .797 & .405 & .243 & .290 \\
\hline Q15 & .778 & .376 & .237 & .197 \\
\hline Q3 & .758 & .537 & .121 & .228 \\
\hline Q14 & .749 & .325 & -.047 & .462 \\
\hline Q7 & .678 & .502 & .456 & .170 \\
\hline Q10 & .625 & .363 & .395 & .491 \\
\hline Q4 & .165 & .885 & .293 & .044 \\
\hline Q5 & .496 & .538 & .517 & -.228 \\
\hline Q6 & -.092 & -.154 & -.920 & -.260 \\
\hline
\end{tabular}




\begin{tabular}{ccc|c|c|}
\hline Q13 & -.242 & -.189 & -.897 & -.097 \\
Q1 & .272 & -047 & .238 & .881 \\
Q2 & .162 & .653 & .095 & .669 \\
\hline
\end{tabular}

To determine the best Kansei knowledge of laser additive manufacturing equipment operators, this paper compiled a rough AHP expert evaluation questionnaire and investigated seven senior operators of laser additive manufacturing equipment. Four of these operators have rich operating experience.

Step 1. Experts evaluate the relative importance of the criteria, form an evaluation matrix $A$ and conduct a consistency test. As an example, the evaluation matrix of the first expert is

$$
A_{1}=\left[\begin{array}{cccc}
1 & 1 / 7 & 1 & 1 / 7 \\
7 & 1 & 7 & 1 / 3 \\
1 & 1 / 7 & 1 & 1 / 9 \\
7 & 3 & 9 & 1
\end{array}\right]
$$

the consistency of the evaluation matrix of the first expert is less than 0.1 , which meets the consistency test requirements.

Step 2. Conduct an AHP survey and construct a group of pairwise comparison matrices. According to Eq. (8), the evaluation matrices of the seven experts were integrated, and the integrated evaluation matrix $\mathrm{B}$ was constructed as follows

$$
B=\left[\begin{array}{cccc}
{[1,1,1,1,1,1,1]} & {\left[3, \frac{1}{7}, \frac{1}{6}, 3,5,5, \frac{1}{5}\right]} & {\left[2,1,1,5, \frac{1}{4}, 6,1\right]} & {\left[\frac{1}{7}, \frac{1}{7}, \frac{1}{9}, \frac{1}{5}, 7, \frac{1}{2}, \frac{1}{3}\right]} \\
{\left[\frac{1}{3}, 7,6, \frac{1}{3}, \frac{1}{5}, \frac{1}{5}, 5\right]} & {[1,1,1,1,1,1,1]} & {\left[1,7,7,2, \frac{1}{5}, 1,3\right]} & {\left[\frac{1}{4}, \frac{1}{3}, \frac{1}{4}, \frac{1}{5}, 1, \frac{1}{6}, 1\right]} \\
{\left[\frac{1}{2}, 1,1, \frac{1}{5}, 4, \frac{1}{6}, 1\right]} & {\left[1, \frac{1}{7}, \frac{1}{7}, \frac{1}{2}, 5,1, \frac{1}{3}\right]} & {[1,1,1,1,1,1,1]} & {\left[\frac{1}{8}, \frac{1}{9}, \frac{1}{7}, \frac{1}{6}, 9, \frac{1}{3}, \frac{1}{7}\right]} \\
{\left[7,7,9,5, \frac{1}{7}, 2,3\right]} & {[4,3,4,5,1,6,1]} & {\left[8,9,7,6, \frac{1}{9}, 3,7\right]} & {[1,1,1,1,1,1,1]}
\end{array}\right]
$$

Step 3. Transform each importance set into a rough set. According to Eqs. (9)-(12), the rough value conversion and normalization were performed, and the constructed rough judgment matrix $M$ was as follows

$$
M=\left[\begin{array}{cccc}
{[1,1]} & {[1.21,3.76]} & {[1.11,3.74]} & {[0.31,2.76]} \\
{[0.98,4.63]} & {[1,1]} & {[1.46,4.92]} & {[0.36,0.70]} \\
{[0.53,1.88]} & {[0.45,2.20]} & {[1,1]} & {[0.32,3.41]} \\
{[1.50,5.98]} & {[2.19,4.61]} & {[3.55,7.49]} & {[1,1]}
\end{array}\right]
$$

Step 4. Calculate the rough weight of each criterion based on Eqs. (13)-(16). The evaluation results of seven experts' Kansei factors are shown in Tab. 7

Tab. 7 Evaluation results of seven experts' Kansei factors 


\begin{tabular}{ccccccc}
\hline Kansei Factors & $w_{g}^{L}$ & $w_{g}^{U}$ & $w_{g}^{L^{\prime}}$ & $w_{g}^{U^{\prime}}$ & $a_{i}^{\prime}$ & $a_{i}$ \\
\hline Humanity & 0.8033 & 2.4960 & 0.2119 & 0.6585 & 0.4352 & 0.2316 \\
Professionalism & 0.8472 & 1.9983 & 0.2235 & 0.5272 & 0.3753 & 0.1997 \\
Personality & 0.5256 & 1.9379 & 0.1387 & 0.5112 & 0.3249 & 0.1729 \\
Safety & 1.8480 & 3.7907 & 0.4875 & 1.0000 & 0.7438 & 0.3958
\end{tabular}

The results in Tab. 7 show that the safety factor, which is 0.3958 , accounts for the highest proportion. This result shows that safety is the most important Kansei factor among the operators of laser additive manufacturing. When conducting emotional fusion design, the effect of safety factors on the design should be first considered to ensure that the design results load the psychological cognition of most people. After that, the order of proportion was the humanity factor, professional factor, and personality factor. It was shown that the operator pays more attention to safety while agreeing with the human feeling.

Through the analysis of the perceptual factors of the operators of the laser additive manufacturing equipment and the related characteristics of the equipment, the Kansei design requirements are resolved from the three aspects of professional needs, safety needs, and human needs. The relative importance weights and design requirements of the Kansei factors obtained after a rough AHP analysis are introduced into the House of Quality. $\boldsymbol{\Delta}$ (1 point), ( 3 points) and $-(5$ points) are used to represent the weak, medium, and strong relationships between user needs and design requirements, respectively. The Kansei factor-design requirement QFD matrix was then constructed. According to Eq. (17) and Eq. (18), the importance value of each design requirement is calculated, as shown in Fig. 5.

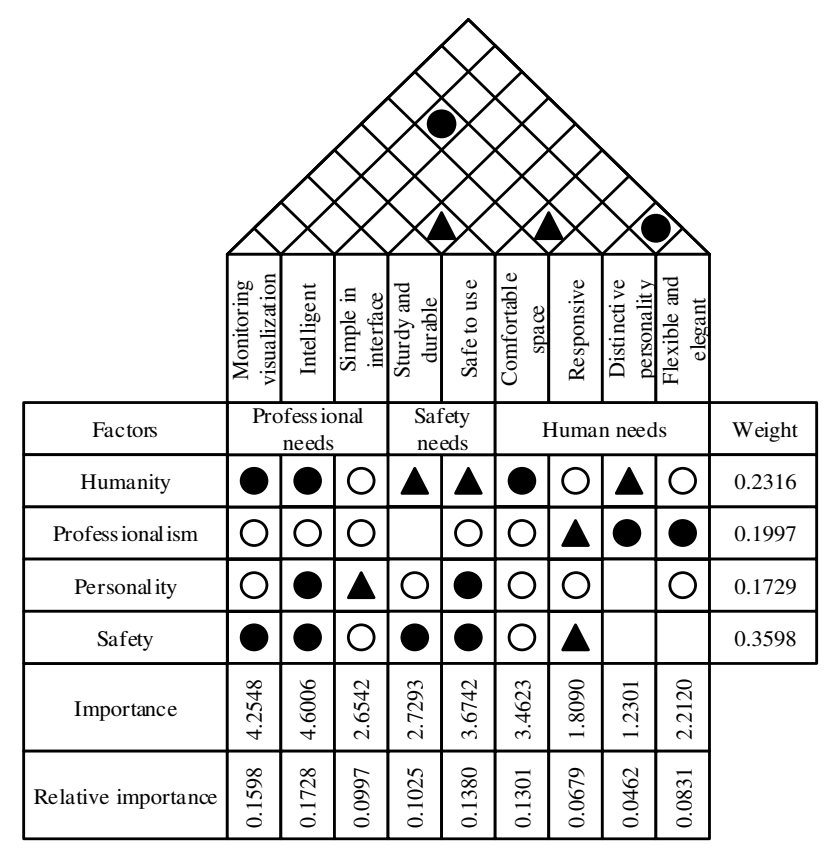

Fig. 5 QFD matrix of Kansei factor-design requirement

According to the results in Fig. 5, intelligence, monitoring visualization, safety in use and space comfort are relatively important design requirements. The contents of the table were consolidated and simplified with lower 
relative importance and similar importance. The distinctive personality is relatively low in importance and partly similar to the smart and elegant in content, so the two are merged into the smart and elegant design requirements. The contents of responsive and intelligent design requirements are similar, and the weight of responsiveness is lower than that of intelligent, so the two are merged into intelligent design requirements. The final design requirements for laser additive manufacturing equipment are intelligent, visualized, safe to use, comfortable space, sturdy and durable, simple interface, flexible and elegant.

The results of the design requirements of laser additive manufacturing equipment are transformed into the functional requirements of axiomatic design, named FR1 through FR7: FR1=intelligence, FR2=visualization, FR3=safe use, FR4=comfortable space, FR5=sturdy and durable, FR6=simple interface, FR7=smart and elegant. For each functional requirement, the corresponding emotional fusion design demands are proposed as the design parameters of axiomatic design. The details are shown in Tab. 8.

Tab. 8 Comparison table of functional requirements and design parameters

\section{Intelligent FR1 The appearance structure has a high degree of integration DP1}

Visualization FR2 Observable running process DP2

Safe to Use FR3 Good protection DP3

Comfortable SpaceFR4 Appearance and structure design is easy for personnel to operate DP4

Sturdy and durable FR5 The structural design is more robust and reliable DP5

Simple Interface FR6 Simple and clear appearance and interface DP6

Flexible and Elegant FR7 Smooth appearance of equipment DP7

Mapping the functional requirements and the design requirements and testing the coupling of the mapping relationship according to the independent axiom, the judgment matrix is obtained as shown below. This matrix is a noncoupling matrix, which meets the requirements of axiomatic design.

$$
\left[\begin{array}{l}
F R_{1} \\
F R_{2} \\
F R_{3} \\
F R_{4} \\
F R_{5} \\
F R_{6} \\
F R_{7}
\end{array}\right]=\left[\begin{array}{lllllll}
1 & 0 & 0 & 0 & 0 & 0 & 0 \\
0 & 1 & 0 & 0 & 0 & 0 & 0 \\
0 & 0 & 1 & 0 & 0 & 0 & 0 \\
0 & 0 & 0 & 1 & 0 & 0 & 0 \\
0 & 0 & 0 & 0 & 1 & 0 & 0 \\
0 & 0 & 0 & 0 & 0 & 1 & 0 \\
0 & 0 & 0 & 0 & 0 & 0 & 1
\end{array}\right]\left[\begin{array}{c}
D P_{1} \\
D P_{2} \\
D P_{3} \\
D P_{4} \\
D P_{5} \\
D P_{6} \\
D P_{7}
\end{array}\right]
$$

Next, decompose the morphological elements of current common laser additive manufacturing equipment and take the morphological elements as the evaluation object and the design requirements as the evaluation indicators to construct a matrix of morphological elements-design requirements. Six experts are invited to score with 1, 3, and 5 points and calculate the importance of each form element. they take this result as a criterion for judging to 
meet the emotional fusion design elements of laser additive manufacturing equipment. Tab. 9 shows the decomposition results of the morphological elements. The first expert in this paper was taken as an example for solving and calculating the morphological element score. The evaluation result of the first expert is shown in Tab. 10.

Tab. 9 Form elements decomposition result

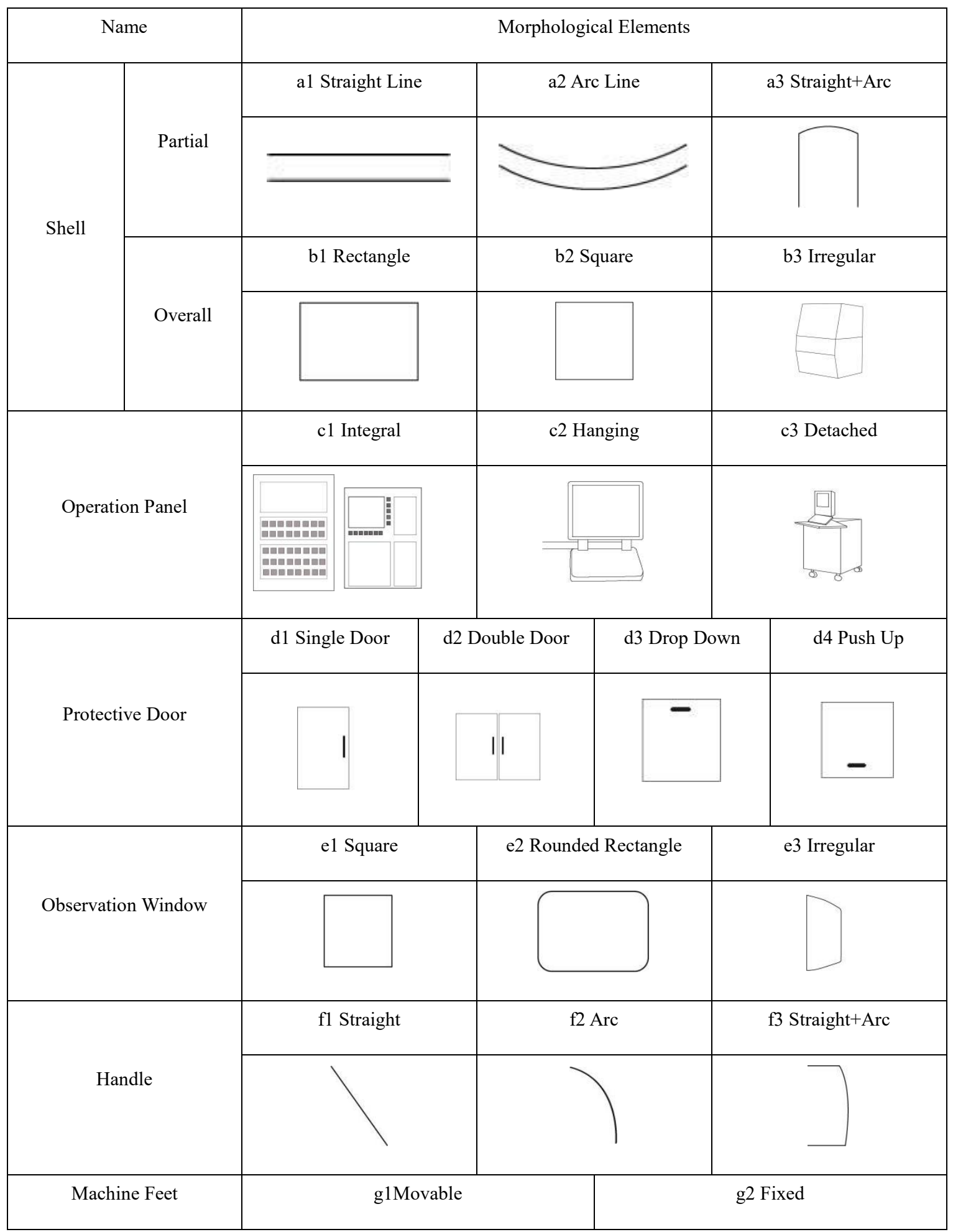






Tab. 10 Evaluation results of the first expert's form elements

\begin{tabular}{l|ccccccccccccccccccccc}
\hline & $\mathrm{a} 1$ & $\mathrm{a} 2$ & $\mathrm{a} 3$ & $\mathrm{~b} 1$ & $\mathrm{~b} 2$ & $\mathrm{~b} 3$ & $\mathrm{c} 1$ & $\mathrm{c} 2$ & $\mathrm{c} 3$ & $\mathrm{~d} 1$ & $\mathrm{~d} 2$ & $\mathrm{~d} 3$ & $\mathrm{~d} 4$ & $\mathrm{e} 1$ & $\mathrm{e} 2$ & $\mathrm{e} 3$ & $\mathrm{f} 1$ & $\mathrm{f} 2$ & $\mathrm{f} 3$ & $\mathrm{~g} 1$ & $\mathrm{~g} 2$ \\
\hline DP1 & 3 & 1 & 5 & 1 & 1 & 3 & 1 & 3 & 3 & 3 & 5 & 1 & 1 & 1 & 3 & 1 & 0 & 0 & 3 & 0 & 0 \\
DP2 & 0 & 0 & 0 & 1 & 1 & 3 & 1 & 3 & 5 & 1 & 3 & 1 & 1 & 5 & 3 & 3 & 0 & 0 & 0 & 3 & 1 \\
DP3 & 1 & 3 & 3 & 1 & 1 & 3 & 5 & 3 & 1 & 5 & 5 & 3 & 1 & 0 & 0 & 0 & 1 & 3 & 5 & 1 & 5 \\
DP4 & 1 & 3 & 5 & 1 & 1 & 5 & 1 & 3 & 3 & 3 & 5 & 1 & 1 & 5 & 3 & 1 & 1 & 3 & 5 & 5 & 3 \\
DP5 & 3 & 5 & 3 & 3 & 3 & 1 & 5 & 3 & 3 & 5 & 3 & 1 & 3 & 5 & 3 & 1 & 0 & 0 & 0 & 1 & 3 \\
DP6 & 3 & 1 & 1 & 0 & 0 & 3 & 3 & 3 & 1 & 3 & 1 & 3 & 3 & 5 & 3 & 1 & 5 & 1 & 3 & 1 & 3 \\
DP7 & 1 & 3 & 5 & 1 & 3 & 5 & 3 & 3 & 5 & 5 & 5 & 1 & 1 & 1 & 3 & 3 & 1 & 3 & 5 & 3 & 3 \\
\hline
\end{tabular}

The scoring result was converted into a matrix of morphological elements-design requirements and normalized, $m=21, n=7$. The results are as follows:

$V=\left[\begin{array}{ccccccc}0.085 & 0 & 0.029 & 0.029 & 0.085 & 0.085 & 0.029 \\ 0.029 & 0 & 0.085 & 0.085 & 0.143 & 0.029 & 0.085 \\ 0.143 & 0 & 0.085 & 0.143 & 0.085 & 0.029 & 0.143 \\ 0.029 & 0.029 & 0.029 & 0.029 & 0.085 & 0 & 0.029 \\ 0.029 & 0.029 & 0.029 & 0.029 & 0.085 & 0 & 0.085 \\ 0.085 & 0.085 & 0.085 & 0.143 & 0.029 & 0.085 & 0.143 \\ 0.029 & 0.029 & 0.143 & 0.029 & 0.143 & 0.085 & 0.085 \\ 0.085 & 0.085 & 0.085 & 0.085 & 0.085 & 0.085 & 0.085 \\ 0.085 & 0.143 & 0.029 & 0.085 & 0.085 & 0.029 & 0.143 \\ 0.085 & 0.029 & 0.143 & 0.085 & 0.143 & 0.085 & 0.143 \\ 0.143 & 0.085 & 0.143 & 0.143 & 0.085 & 0.029 & 0.143 \\ 0.029 & 0.029 & 0.085 & 0.029 & 0.029 & 0.085 & 0.029 \\ 0.029 & 0.029 & 0.029 & 0.029 & 0.085 & 0.085 & 0.029 \\ 0.029 & 0.143 & 0 & 0.143 & 0.143 & 0.143 & 0.029 \\ 0.085 & 0.085 & 0 & 0.085 & 0.085 & 0.085 & 0.085 \\ 0.029 & 0.085 & 0 & 0.029 & 0.029 & 0.029 & 0.085 \\ 0 & 0 & 0.029 & 0.029 & 0 & 0.143 & 0.029 \\ 0 & 0 & 0.085 & 0.085 & 0 & 0.029 & 0.085 \\ 0.085 & 0 & 0.143 & 0.143 & 0 & 0.085 & 0.143 \\ 0 & 0.085 & 0.029 & 0.143 & 0.029 & 0.029 & 0.085 \\ 0 & 0.029 & 0.143 & 0.085 & 0.085 & 0.085 & 0.085\end{array}\right]$

According to the calculation steps of the GRA-TOPSIS method, the positive and negative ideal solution sets of the standardized matrix of the first expert were solved, and the gray correlation coefficient was calculated. According to Eq. (30) and Eq. (31), the closeness of each morphological element to the positive and negative ideal solutions was calculated after integration, and nondimensional processing was performed. The weight results of the first expert's equipment form factors are shown in Tab. 11. In the same way, the weight results of the remaining five experts are solved. The weight results of the six experts are integrated and averaged. The final weight results shown in Tab. 12 are obtained. 
Tab. 11 Weight of the first expert's equipment form elements

\begin{tabular}{|c|c|c|c|}
\hline Element & Score & Elements & Score \\
\hline a1 & 0.4125 & $\mathrm{~d} 3$ & 0.3880 \\
\hline a2 & 0.4578 & $\mathrm{~d} 4$ & 0.3870 \\
\hline a3 & 0.5627 & e1 & 0.5884 \\
\hline b1 & 0.3245 & e2 & 0.5224 \\
\hline b2 & 0.3524 & e3 & 0.3737 \\
\hline b3 & 0.6033 & $\mathrm{fl}$ & 0.3658 \\
\hline $\mathrm{c} 1$ & 0.5245 & $\mathrm{f} 2$ & 0.3466 \\
\hline c2 & 0.5828 & f3 & 0.5422 \\
\hline c3 & 0.5793 & g1 & 0.4306 \\
\hline d1 & 0.6202 & g2 & 0.4958 \\
\hline $\mathrm{d} 2$ & 0.6636 & & \\
\hline
\end{tabular}

Tab. 12 Final weight result of form elements

\begin{tabular}{|c|c|c|c|}
\hline Element & Score & Elements & Score \\
\hline a1 & 0.5347 & $\mathrm{~d} 3$ & 0.4118 \\
\hline a2 & 0.5317 & $\mathrm{~d} 4$ & 0.3957 \\
\hline $\mathrm{a} 3$ & 0.5891 & e1 & 0.4269 \\
\hline b1 & 0.4458 & e2 & 0.6040 \\
\hline b2 & 0.4746 & e3 & 0.3395 \\
\hline b3 & 0.3660 & $\mathrm{fl}$ & 0.3658 \\
\hline $\mathrm{c} 1$ & 0.5513 & $\mathrm{f} 2$ & 0.3466 \\
\hline $\mathrm{c} 2$ & 0.5194 & $\mathrm{f} 3$ & 0.5422 \\
\hline c3 & 0.4533 & g1 & 0.4306 \\
\hline $\mathrm{d} 1$ & 0.6021 & g2 & 0.4958 \\
\hline $\mathrm{d} 2$ & 0.6070 & & \\
\hline
\end{tabular}

\section{Discussion}


According to Tab. 12, to meet the psychological and emotional needs of personnel, the Kansei engineering optimization design program of laser additive manufacturing equipment should have the following morphological elements: the appearance of the equipment is primarily a square shell with straight and arc lines and an integral operation panel. The double-opening protective door is equipped with a rounded rectangular observation window, and each cabin door is equipped with straight and arc line handles. The equipment is adaptable with movable machine feet. Based on the determined morphological elements, the two design programs shown in Fig. 6 (a) and (b) are proposed.

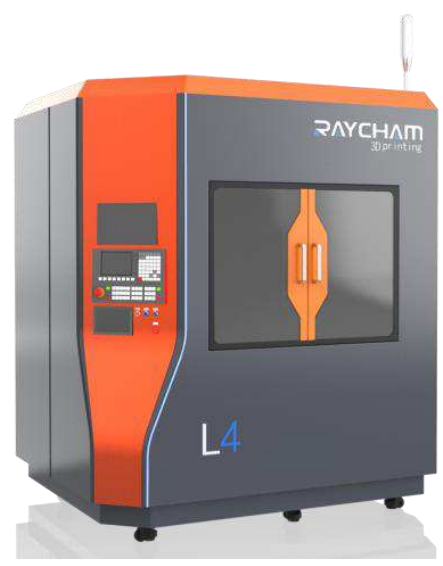

(a) First design program of LDM4030

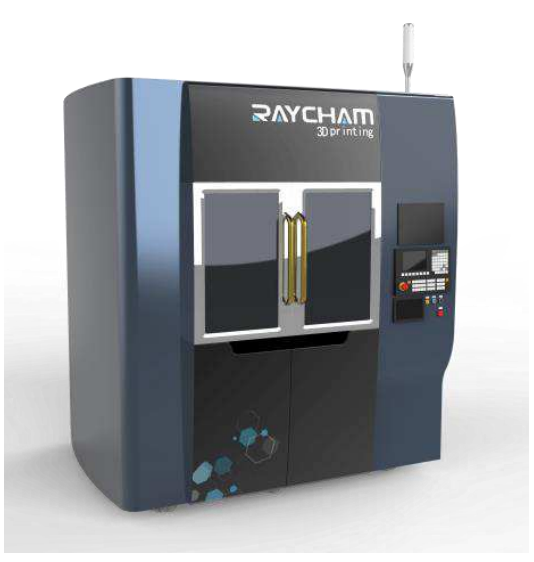

(b) Second design program of LDM4030

Fig. 6 Kansei optimal design program of LDM4030 based on axiomatic design

According to information axioms, we first compared the satisfaction degree of the emotional needs of personnel between the two design optimization programs and the original program. Tab. 13 shows the comparison results of the satisfaction degree of the emotional needs of personnel. Both programs were designed according to the morphological elements of laser additive manufacturing equipment that meet the psychological and emotional needs of personnel, and these needs were met.

Tab. 13 Comparison results of the satisfaction degree of the emotional needs of personnel.

\begin{tabular}{|c|c|c|c|}
\hline Morphological Elements & First Design Program & Second Design Program & Original Program \\
\hline Square shell & Yes & Yes & Yes \\
\hline Straight and arc lines & Yes & Yes & Yes \\
\hline Integral operation panel & Yes & Yes & No \\
\hline Double-opening protective & Yes & & No \\
\hline door & Yes & Yes & No \\
\hline Rounded rectangular \\
observation window
\end{tabular}


Compared with those of the first program, the second program has smoother lines, but the structural design of the protective door is more complicated, and the process would be relatively complicated in the subsequent manufacturing process. The first program has certain advantages over the second program in terms of intelligent integration requirements, simplicity, and clarity of appearance. The main color of gray and black gave people a sense of heaviness, security, and higher intelligence. The use of warm color lines is smoother and softer, which people have a higher affinity for. According to Eq. (37), the actual and feasible needs of the users that are met by the first program are greater than those of the second program, as shown in Fig. 7, $P_{1}>P_{2}$. The information content required in the design of the first program, $I_{1}$ is less than that of the second $I_{2}$. It is judged that the first program is the optimal design based on the information axioms.

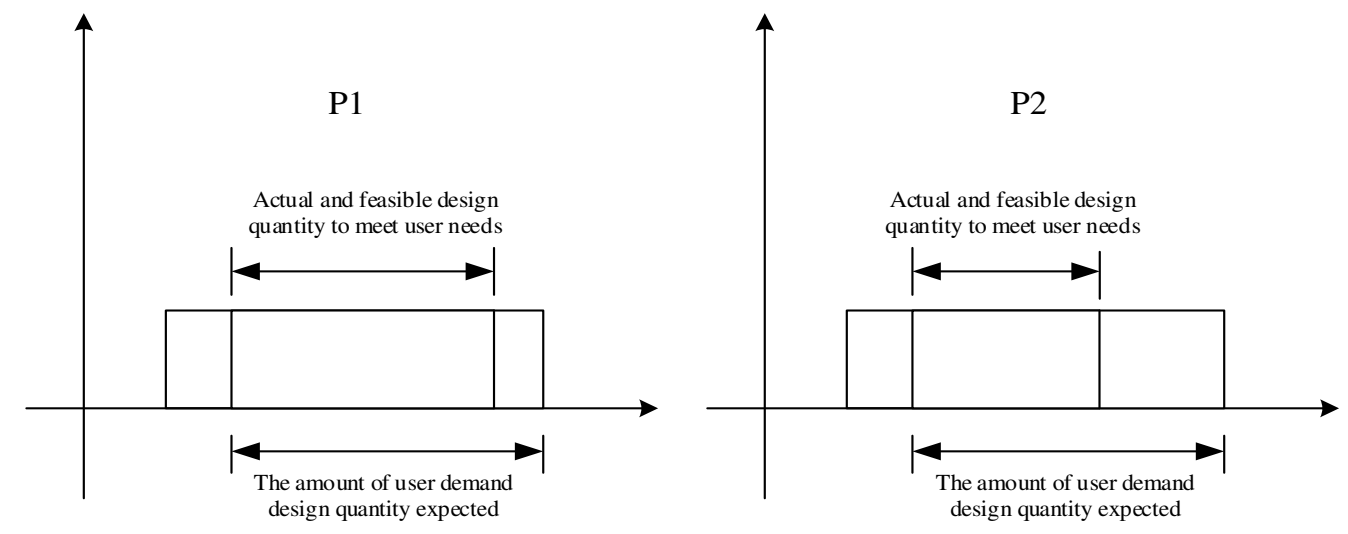

Fig.7 Comparison of actual and feasible demand design

The four Kansei factors obtained through Kansei semantic experiments are all important starting points for the design process of laser additive manufacturing equipment. Additionally, the combination of human emotion design is well realized in determining the needs of the user domain. In the design of the functional domain and the physical domain, the mapping relationship between human emotion-design and requirements-design elements is accurately realized through QFD and independent axioms. The design elements of the equipment are accurately integrated into emotional factors and realize the close integration of personnel emotional needs and equipment. Therefore, the optimal design program (the first program) could well integrate the human emotion factors into the equipment design. It is of great significance for improving the design level of laser additive manufacturing equipment and improving the pleasantness of the use process.

\section{Conclusion}

This paper studies the fusion design of laser additive manufacturing equipment human-machine system cognitive interaction and human emotion, and it proposes a Kansei-AD emotion fusion design optimization method. Based on the analysis of the operator's emotional cognitive process and the representation of psychological and emotional needs, the emotional fusion design process of laser additive manufacturing equipment is divided into four parts: user domain, functional domain, physical domain, and process domain through axiomatic design. Based on the application of the Kansei semantic difference experiment to obtain the psychological and emotional needs of personnel, the Kansei design requirements are calculated via the rough AHP and QFD methods. Aiming at the problem of inaccurate mapping between emotional factors and design elements in traditional Kansei engineering design, the design needs are transformed into axiomatic design functional requirements, and the design 
requirements are transformed into axiomatic design parameters. Independent axioms are used to judge the relationship between the two coupling relationships. The GRA-TOPSIS method is used to construct a morphological elements-design requirements matrix to solve the optimal morphological elements. The optimal design plan with information axioms is screened to determine the final design plan. This paper takes LDM4030 coaxial powder feeding laser additive manufacturing equipment as an example to verify the effectiveness of the proposed method. The results show that the optimized design scheme has a larger amount of feasible demand design and less design information, which can fully meet the emotional needs of users of laser additive manufacturing equipment. It is of great significance for improving the emotional fusion design level and human-computer interaction efficiency of laser additive manufacturing equipment.

Concerning future research, this paper primarily takes the morphological interaction process as the research object to design emotional fusion. The interaction process of personnel will also have a certain effect on psychological and emotional factors. Therefore, the design of operational interaction emotion fusion will be the focus of future research.

\section{Availability of data and materials}

All data generated or analysed during this study are included in this published article [and its supplementary information files].

\section{Competing interests}

The authors declare that they have no competing interests.

\section{Funding}

Supported by '2016 Green Manufacturing System Integration Project of Ministry of Industry and Information Technology of China'(under grant 201675514), 'Research on the Theory and Method of Quality Intelligent Control in the Remanufacturing Process of Waste Mechanical and Electrical Products'(under grant 51305279), 'Program for the Top Young Innovative Talents of Liaoning Revitalization Talent Program' (under grant XLYC1807211), and 'Program for the Top Young and Middle-aged Innovative Talents of Shenyang'(under grant RC190148).

\section{Authors' contributions}

MMY analyzed the formation process of emotional needs and the combination of kansei-AD, and was a main contributor in writing the manuscript. JXY and LWJ were in change of the whole trail. WX and ZC were responsible for drawing the design plan. LD and YGZ were responsible for data calculation. All authors read and approved the final manuscript.

\section{Acknowledgements}

The authors sincerely thanks to the Key Laboratory of Intelligent Manufacturing and Industrial Robot of Liaoning Province for supporting this manuscript.

\section{References}

[1] FU Qian-wen,LV Jian,TANG Shi-hao,XIE Qing-sheng.Optimal Design of Virtual Reality Visualization Interface Based on Kansei Engineering Image Space Research.Symmetry, 2020, 12(10): 1722.
[2] WANG W M, WANG J W, LI Z,TIAN ZG,TSUI E. Multiple affective attribute classification of online customer product reviews: A heuristic deep learning method for supporting Kansei engineering. 
Engineering Applications of Artificial Intelligence, 2019, 85: 33-45.

[3] ALANIZ T, BIAZZO S. Emotional design: the development of a process to envision emotion-centric new product ideas.Procedia Computer Science, 2019, 158:474-484.

[4] KONGPRASERT N, BUTDEE S. A methodology for leather goods design through the emotional design approach.Journal of Industrial and Production Engineering, 2017, 34(3):170-179.

[5] SIMEUNOVIC N,ALEXANDRE G,AURELIEN B,FAVART C,YANAGISAWA H,JEAN C.Kansei Design approach applied to new concept development stage: Establishing communication between automated driving vehicles and their surroundings.Advances in Intelligent Systems and Computing,2018,739:277-288.

[6] KIM W,KO T,RHUI I,et al.Mining affective experience for a Kansei design study on a recliner.Applied Ergonomics,2019,74:145-153.

[7] GUO Fu, Liu W L, Cao Y, et al. Optimization design of a webpage based on Kansei engineering. Human Factors and Ergonomics in Manufacturing \& Service Industries, 2016, 26(1): 110-126.

[8] VIEIRA J,OSORIO JMA,MOUTA S,DELGADO P,PORTINHA A.Kansei engineering as a tool for the design of in-vehicle rubber keypads.Applied Ergonomics,2017,61:1-11.

[9] LI Rui,ZHANG Ji-xiao.Design Methods of Panel for NC Machine Tools Based on Emotional Design.Packaging Engineering,2017,38(06):92-95.(In Chinese)

[10] ZENG Dong,LIU Peng,YV Xin-tao,LUO Wei,WANG Kang,YANG Jie.A Building Method of User Mental Model and Its Application in Fire Extinguisher Design.Packaging Engineering,2019,40(16):140-144,150.(In Chinese)

[11] JIA Dang-ping,JIN Jian,GENG Qian,DENG Si-yv.A Kansei Engineering Integrated Approach for Customer-needs Mining from Online Product Reviews.Journal of the China Society for Scientific and Technical Information,2020,39(03):308-316.(In Chinese)

[12] CHENG Yong-sheng,XV Xiao-qi,BU Jun,TANG Gang.Evaluation method of automobile modeling image based on $\mathrm{KE}$ and AHP.Modern Manufacturing Engineering,2020(07):102-109.(In Chinese)

[13] WANG Xin-ting,WANG Can,WANG Huan-huan,HE Rui.Modeling Design of Electric Scooter for the Elderly Based on the Theory of
Quantification-1 Type.Machinery Design \&

Manufacture,2020(07):165-169.(In Chinese)

[14] SHIEH M D, LI Yong-feng, YANG Chih-chieh. Comparison of multi-objective evolutionary algorithms in hybrid Kansei engineering system for product form design. Advanced Engineering Informatics, 2018, 36: 31-42.

[15] PARK JY,ABDEL-ATY M,WU Yi-na,MATTEI I.Enhancing In-Vehicle Driving Assistance Information Under Connected Vehicle Environment.IEEE Transactions on Intelligent Transportation Systems,2018,11(99):1-10.

[16] SUTONO SB,ABDUL-RASHID SH,TAHA Z,SUBAGYO,AOYAMA H.Integration of grey-based Taguchi method and principal component analysis for multi-response decision-making in Kansei engineering.European Journal of Industrial Engineering,2017(11):205-227.

[17] HARTONO M. The modified Kansei Engineering-based application for sustainable service design. International Journal of Industrial Ergonomics, 2020, 79: 102985.

[18] LI Lan-you,LU Jin-gui,ZHANG Jian-de.Kansei image design on product genes basis.Journal of Nanjing Tech University(Natural Science Edition),2019,41(01):71-78,88.(In Chinese)

[19] WANG Xiao-chun,ZHOU Meng-xi.Construction of Picture Book's Emotional Design Model and Evaluation Index System.Journal of Beijing University of Posts and Telecommunications(Social Sciences Edition),2020,22(03):87-93.(In Chinese)

[20] Hu Ming-cai,Guo Fu,Duffy VG,REN Z,YUE Peng.Constructing and measuring domain-specific emotions for affective design: a descriptive approach to deal with individual differences.Ergonomics,2020,63(05):563-578.

[21] WANG Hao-qi,ZHANG Xu,Tang Cheng-tong.Model-based Axiomatic Design Approach for Complex Engineering Systems.Journal of Mechanical Engineering,2018,54(07):184-198.(In Chinese)

[22] CHEN Xi, LI Zhi-wu, FAN Zhi-ping, ZHOU Xiao-yang,ZHANG Xiao. Matching demanders and suppliers in knowledge service: A method based on fuzzy axiomatic design. Information Sciences, 2016, 346: 130-145. 
[23] LIN Chao-qun,FAN Shu hai,CHEN Peng,ZHOU Ce.Axiomatic Design of Mixed Job Shop Layout Based on Digital Factory.Modular Machine Tool \& Automatic Manufacturing Technique,2019(08):16-18,38.(In Chinese)

[24] REDDY A,OWNSWORTH T,KING J,SHIELDS C.A biopsychosocial investigation of changes in self-concept on the Head Injury Semantic Differential Scale.Neuropsychological Rehabilitation,2017,27(08):1103-1123.

[25] KIM K,PROCTOR RW,SALVENDY G.Emotional factors and physical properties of ballpoint pens that affect user satisfaction: Implications for pen and stylus design.Applied Ergonomics,2020,85:103067.

[26] Riaz M, Davvaz B, Firdous A, et al. Novel concepts of soft rough set topology with applications. Journal of Intelligent \& Fuzzy Systems,
2019, 36(4): 3579-3590.

[27] ZHU Guo-niu,HU Jie,QI Jin,GU Chao-chen,PENG Ying-hong. An integrated AHP and VIKOR for design concept evaluation based on rough number. Advanced Engineering Informatics,2015,29(3):408-418.

[28] SALONITIS K. Design for additive manufacturing based on the axiomatic design method. The International Journal of Advanced Manufacturing Technology, 2016, 87(1-4): 989-996.

[29] XI Zhi-fei,XV An,KOU Ying-xin,.Air combat threat assessment based on improved GRA-TOPSIS.Journal of Beijing University of Aeronautics and Astronautics,2020,46(02):388-397.(In Chinese)

[30] QUAN Hua-feng, LI Shao-bo, WEI Hong-jing, HU Jian-jun. Personalized Product Evaluation Based on GRA-TOPSIS and Kansei Engineering. Symmetry, 2019, 11(7): 867. 
Figures



\section{Figure 1}

Cognitive process model of the laser additive manufacturing equipment operator 


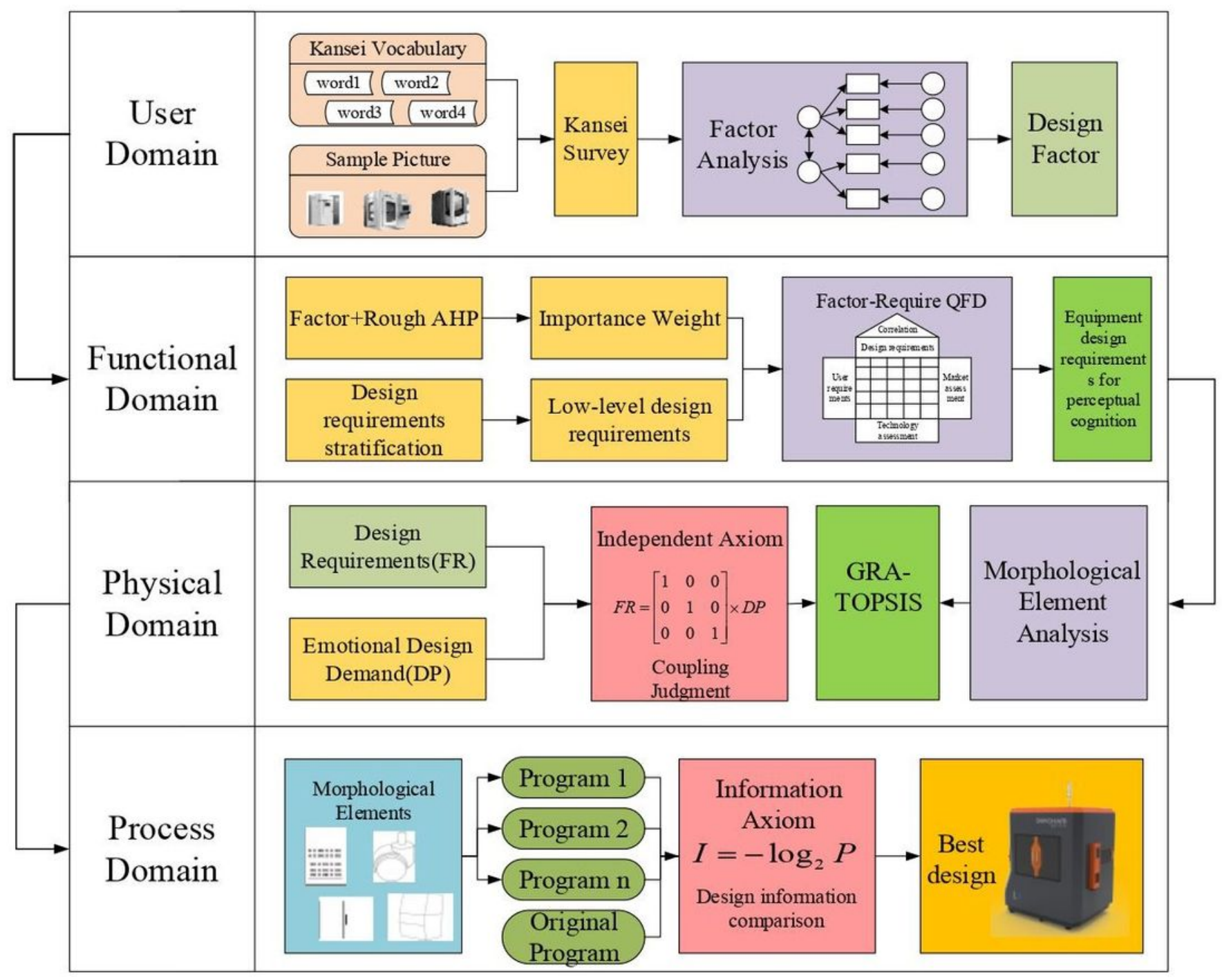

Figure 2

Emotional fusion and design optimization model of laser additive manufacturing equipment 


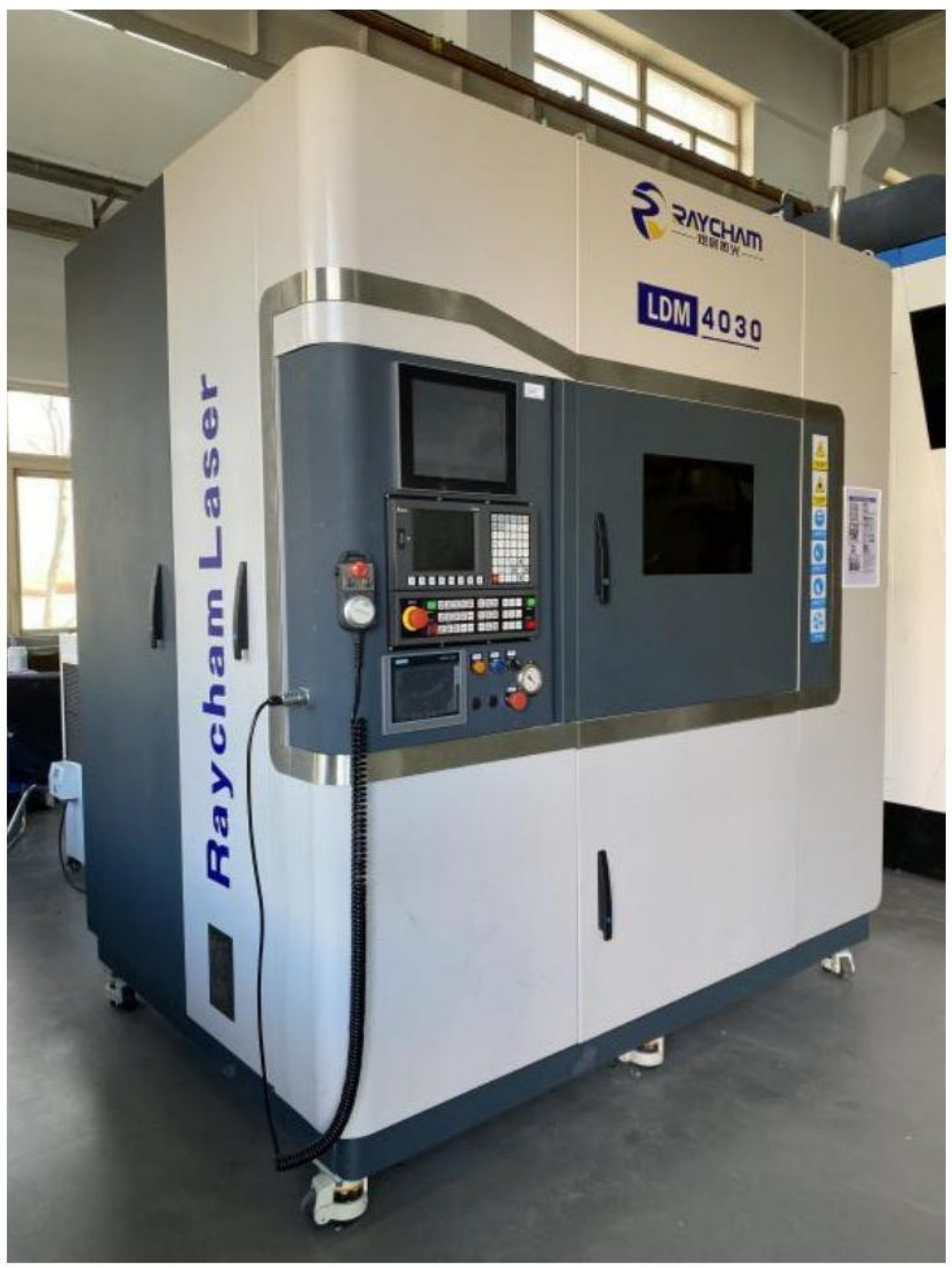

Figure 3

LDM4030 coaxial powder feeding laser additive manufacturing equipment 




Figure 4

Factor analysis lithograph results 


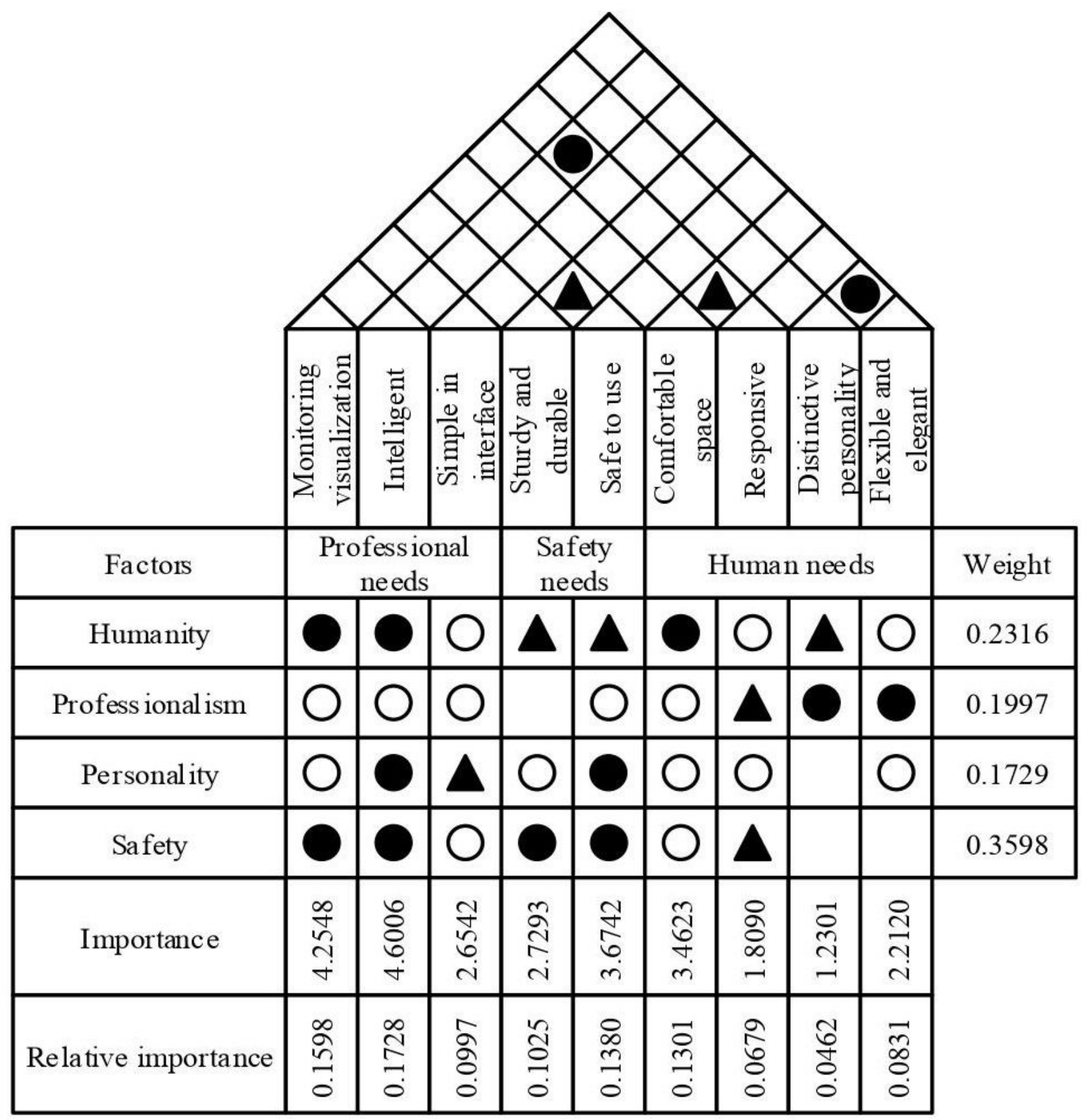

Figure 5

QFD matrix of Kansei factor-design requirement 


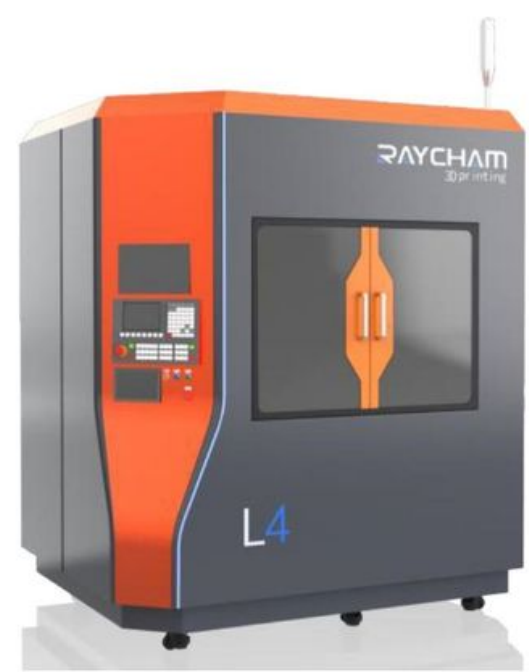

(a) First design program of LDM4030

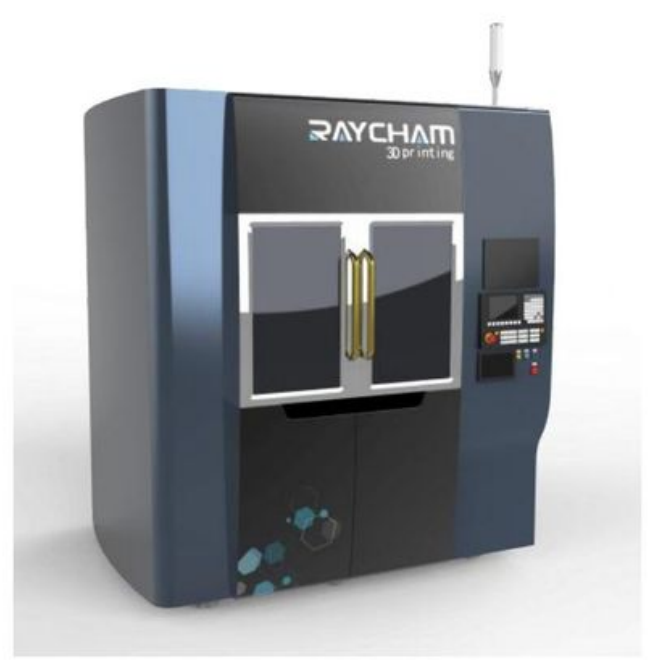

(b) Second design program of LDM4030

\section{Figure 6}

Kansei optimal design program of LDM4030 based on axiomatic design
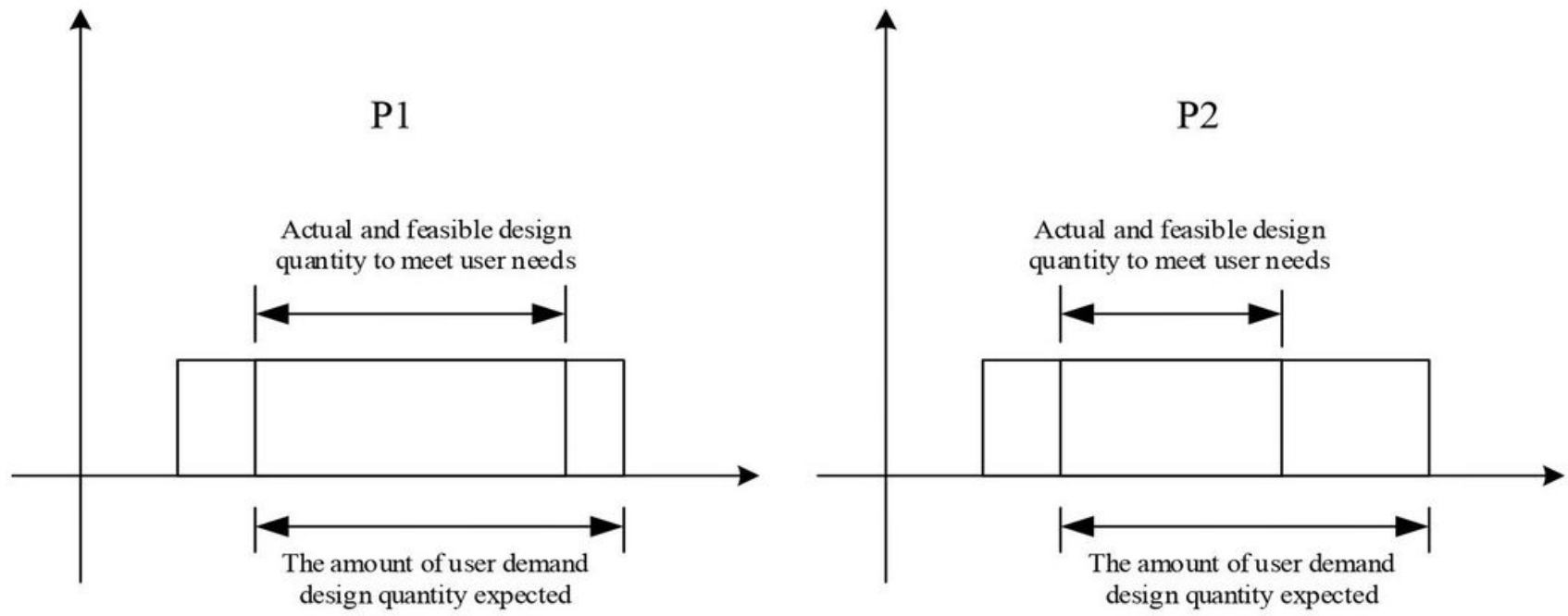

Figure 7

Comparison of actual and feasible demand design 